\title{
WAGE EQUALIZATION AND REGIONAL MISALLOCATION: EVIDENCE FROM ITALIAN AND GERMAN PROVINCES
}

\author{
Tito Boeri \\ Andrea Ichino \\ Enrico Moretti \\ Johanna Posch \\ Working Paper 25612 \\ http://www.nber.org/papers/w25612 \\ NATIONAL BUREAU OF ECONOMIC RESEARCH \\ 1050 Massachusetts Avenue \\ Cambridge, MA 02138 \\ February 2019, Revised January 2020
}

We thank Michael Burda, Zach Bleemer, Christian Dustmann and seminar participants at the Fondazione De Benedetti, the OECD and the University of Rome "La Sapienza" for helpful comments and suggestions. Tito Boeri is at Bocconi University, Andrea Ichino is at the European University Institute, Enrico Moretti is at the University of Berkeley and Johanna Posch it at the Analysis Group. The views expressed herein are those of the authors and do not necessarily reflect the views of the National Bureau of Economic Research.

NBER working papers are circulated for discussion and comment purposes. They have not been peer-reviewed or been subject to the review by the NBER Board of Directors that accompanies official NBER publications.

(C) 2019 by Tito Boeri, Andrea Ichino, Enrico Moretti, and Johanna Posch. All rights reserved. Short sections of text, not to exceed two paragraphs, may be quoted without explicit permission provided that full credit, including $(\odot$ notice, is given to the source. 
Wage Equalization and Regional Misallocation: Evidence from Italian and German Provinces Tito Boeri, Andrea Ichino, Enrico Moretti, and Johanna Posch

NBER Working Paper No. 25612

February 2019, Revised January 2020

JEL No. J0,R1

\section{ABSTRACT}

Italy and Germany have similar geographical differences in productivity - North more productive than South in Italy; West more productive than East in Germany - but have adopted different models of wage bargaining. Italy sets wages based on nationwide contracts that allow for limited local wage adjustments, while Germany has moved toward a more flexible system that allows for local bargaining. The Italian system has significant costs in terms of forgone aggregate earnings and employment because it generates a spatial equilibrium where workers queue for jobs in the South and remain unemployed while waiting. Our findings are relevant for other European countries.

Tito Boeri

Bocconi University

IGIER

Via Salasco 5

20136 Milano, ITALY

tito.boeri@unibocconi.it

Andrea Ichino

European University Institute

Villa La Fonte, Via delle Fontanelle 18, 50014 San Domenico di Fiesole (FI)

Italy

Andrea.Ichino@EUI.eu

\author{
Enrico Moretti \\ University of California, Berkeley \\ Department of Economics \\ 549 Evans Hall \\ Berkeley, CA 94720-3880 \\ and CEPR \\ and also NBER \\ moretti@econ.berkeley.edu \\ Johanna Posch \\ European University Institute \\ Department of Economics \\ Via delle Fontanelle 18 \\ San Domenico di Fiesole 50014 \\ Italy \\ johanna.posch@eui.eu
}




\section{Introduction}

Wage inequality is large and rising in many countries. Different countries have different labor market institutions to try to mitigate labor market inequality, including minimum wages, subsidies for low wage workers like the Earned Income Tax Credit, and unions contracts.

In Western European countries, multi-firm collective bargaining agreements are common practice and cover the majority of workers. In 12 Western European countries out of 18, multi-firm collective bargaining covers more than 70 per cent of the workers. Only in Ireland (where there is, however, strong co-ordination at the industry level) and in the UK plant-level agreements are dominant in the structure of bargaining (OECD, 2017) although the two countries differ on how binding their national agreements are (Du Caju et al., 2008). Typically, firms and unions belonging to a specific sector bargain over an occupation-specific wage schedule. This wage schedule applies to all workers in that sector, irrespective of their location and of whether or not they belong to a union. ${ }^{1}$ Most countries have "excess coverage" of collective bargaining, that is, a fraction of workers involved by the agreements negotiated by the unions (coverage) significantly larger than the fraction of workers members of a trade union (union density). Excess coverage is present in Austria, Belgium, Denmark, Finland, France, Germany, Greece, Iceland, Ireland, Italy, Luxembourg, Netherlands, Norway, Portugal, Slovenia, Spain, Sweden and Switzerland (OECD, 2017).

The objective of this extended coverage is to equalize salaries across employers, "levelling the playing field across firms" (OECD, 2018b), and reducing inequality. A vast literature on collective bargaining (Flanagan, 1999) and on the determinants of income distributions (Atkinson and Brandolini, 2006) considers centralized wage setting an institution reducing earning and income inequalities. However, this literature rather systematically neglects "inflation across space", within country differences in the purchasing power of the same nominal wage level.

In this paper, we investigate an important but relatively under-researched feature of collective bargaining systems. We argue that while centralized wage bargaining may be successful at compressing nominal wage inequality in a country, it can also create costly imbalances between cities and regions, with negative correlations between real wages and productivity, as well as higher income inequality. In the presence of geographic differences in productivity across cities and regions, nominal wage equalization across localities can lead to lower employment and earnings in low productivity areas and in the

\footnotetext{
${ }^{1}$ As acknowledged by Card et al. (2004), there is de facto no distinction between union and nonunion sectors in these countries.
} 
aggregate.

We study the local and aggregate effects of national wage bargaining systems in Italy and Germany. Italy and Germany represent two useful case studies. Both make extensive use of collective bargaining agreements, but the level of resulting wage flexibility is markedly different. Italian nationwide sectoral contracts are more binding and allow for only limited local wage adjustments. This means that within each sector, firms in high productivity and low productivity areas face largely the same wage schedule. ${ }^{2}$ Germany previously had a similar wage setting system, but after reunification it made it more flexible. Due to concerns about lower productivity in the East, since 1996 Germany has adopted so-called "opening clauses" that allow firms to negotiate wages locally with unions, deviating from nationwide agreements (Schnabel, 1998).

In the first part of the paper, we study the relationship between local firm productivity and local wages, non-employment rates, and cost of living. Our geographic unit of analysis is a local labor market, defined as an Italian "Province" (103 in total) or a German "Spatial Planning Region -“Raumordnungsregion" (96 in total). Empirically, Italy and Germany have a similar cross-province standard deviation in mean firm productivity, as measured by firm value added. In Italy, firm value added is significantly higher in the North than in the South: in 2014, the gross value added per worker in an average firm of Milano, for example, was $71 \%$ above the value added in an average firm of Cosenza, in the southern region of Calabria. In Germany, productivity is significantly higher in the West than in the East: the value added per worker in an average firm in Munich is 83\% above the value added in an average firm of North Thuringen in East Germany. ${ }^{3}$ In Italy, the North-South productivity gap reflects long-lasting historical differences in transportation infrastructure, distance from European markets, efficiency of local governments and local policies, criminal activity, and cultural norms, while in Germany, the East-West gap likely reflects half a century of Communist rule in the East as well as other historical factors. ${ }^{4}$

While Italy and Germany have similar geographic distribution of firm productivity,

\footnotetext{
${ }^{2}$ While firms can increase wages above the national contract schedule, they cannot lower them in most cases. We provide details on these institutions in the next Section.

${ }^{3}$ Similar geographic differences exist in most countries. In the US, total factor productivity of firms in cities at the top of the TFP distribution is double that of cities at the bottom of the distribution (Hornbeck and Moretti, 2018).

${ }^{4}$ As we will show, the North-South productivity gap in Italy is remarkably similar to the West-East productivity gap in Germany. In 2014, the difference in mean value added between the Northern Italian and Southern Italian firms was 19.0\%. The corresponding difference between West and East German firms was almost identical: $19.9 \%$. In this paper, we will take these differences as given. Our analysis will focus on the effects of these differences, rather than on their causes. The literature on regional productivity differences is immense. Examples for Italy include Banfield, 1958, Putnam et al., 1993, Ichino and Maggi, 2000, Guiso et al., 2004 and, more recently, Buonanno et al., 2015, Bigoni et al., 2016, Adda, 2018. An example for Germany is Burda and Hunt, 2001).
} 
they have important differences in the geographic distribution of nominal wages, likely reflecting wage bargaining differences in the two countries. In Italy, there is a much stronger degree of wage equalization across provinces than in Germany. For example, after controlling for worker characteristics the 90-10 percentile difference in mean wages across provinces is $42.9 \%$ in Germany, more than four times larger than the $10.3 \%$ difference in Italy. The mean wage difference between the North and the South in Italy is $4.2 \%$, while the mean West-East difference in Germany is seven times larger: $28.2 \%$, despite similar productivity differences.

Crucially, we find a marked difference in the relationship between local productivity and local nominal wages in the two countries. If wages can fully adjust, we should see a tight relationship between the two, with areas that enjoy higher firm productivity also having proportionally higher mean nominal wages. This is indeed the case in the US (Hornbeck and Moretti, 2018). By contrast, if wages are prevented from fully adjusting, we should see a weaker relationship. In the extreme case of fully-binding national contracts with complete nominal wage equalization, we should see no relationship at all. When we regress log mean nominal wage (adjusted for workers characteristics) on log value added across provinces, we find an elasticity of wages with respect to value added of 0.19 in Italy and 0.73 - almost four times larger - in Germany. Thus, German firms appear to be significantly more able to adjust nominal wages to local productivity than Italian firms.

A simple model indicates that wage bargaining differences in the two countries should result in differences in the geographical distribution of non-employment rates, housing costs and real wages. First, in Italy, where wages cannot fully adjust, provinces with low productivity should have higher non-employment rates. The reason is that firms in provinces where productivity is low need to pay wages above the local market-clearing level. This should be less true in Germany, where wages can adjust more to local productivity. When we regress local non-employment rate on local value added we find that the elasticity of non-employment rates with respect to value added is negative in both countries - indicating that provinces with lower value added have higher non-employment rates - but the elasticity in Italy is $-1.43(0.03)$, almost six times larger (in absolute value) than Germany's -0.25 (0.02) elasticity. Our findings are not driven by the existence of an informal sector in Italy.

Second, since workers can move across regions, low productivity provinces should have lower housing prices, both in Italy and Germany. Empirically this is the case: we find a positive relationship between housing prices and local productivity.

Third, there are striking implications for real wages, defined as nominal wages de- 
flated by the local cost of living. In Italy we find a negative relationship between real wages and local value added. Despite having higher productivity, provinces in the North have lower real wages than provinces in the South, since the South has low housing costs but similar nominal wages. ${ }^{5}$ By contrast, in Germany, we do not see that real wages in the West are lower than in the East, since nominal wages are spatially more flexible.

This means that employed Italians are better off working in the South in terms of purchasing power. However, the probability of having a job is higher in the North. One way to think about geographic differences in Italy is that national wage contracts have created a spatial equilibrium where workers queue for jobs in the South. If they find a job, they are better off than their colleagues in the North in terms of real wages, but while queued they remain not-employed.

Overall, the current wage-setting system in Italy appears inefficient. If nominal wages were allowed to reflect local productivity, nominal wages would decline in low productivity provinces, and employment there would increase, resulting in an overall increase in employment in the country. ${ }^{6}$

In the last part of the paper, we quantify the aggregate costs in terms of forgone aggregate earnings and employment. We consider what would happen if Italy adopted a system similar to Germany's. We provide estimates from a counterfactual scenario in which the Italian relationships between wages and value added and between non-employment and value added are the same as those observed in Germany. To be clear, we do not assume that wages or employment or value added are the same in the two countries; rather, we apply to Italy the elasticity of wages with respect to value added and the elasticity of non-employment with respect to value added that we estimate for Germany. ${ }^{7}$ We find that average wages in Southern provinces would decrease by an average of 5.9\% (or 53 cents an hour), while Southern employment would increase by 12.85 percentage points. On net, aggregate earnings in Southern provinces would increase on average by $16.6 \%$, or 114 Euros a month. Nationwide, we estimate that aggregate employment would increase by 5.77 percentage points and aggregate earnings would increase by $7.45 \%$. This amounts to around 600 euros per year for each working-age adult. We also consider an

\footnotetext{
${ }^{5}$ See Jappelli and Pistaferri (2010) for an analysis of how consumption inequality relates to income inequality in Italy.

${ }^{6}$ If the elasticity of labor demand is larger than one, aggregate labor earnings would increase. Intuitively, an elastic labor demand means that the increase in employment in low productivity areas more than offsets the decline in wages. Labor demand - at least in the traded sector - is probably elastic in the case of an open economy like Italy, which is fully integrated in European product markets.

${ }^{7}$ Specifically, we set the counterfactual wages and the counterfactual employment in each Italian province based on the province observed value added and the elasticity of wages with respect to value added and employment with respect to value added that we estimate for Germany.
} 
alternative counterfactual scenario where we allow for full adjustment of local wages to local productivity, and find similar estimates.

We conclude that in the aggregate, allowing union contracts some degree of local flexibility would improve the efficiency of labor allocation in Italy, resulting in increased employment and per capita labor income. There would also be distributional consequences, as currently-employed workers in the South would enjoy lower nominal and real wages. ${ }^{8}$

Our findings are relevant to countries other than Italy and Germany, as the Italian and German system are by no means unique. Broadly speaking, France, Belgium, Portugal, Finland, Iceland, and Slovenia have a system similar to the Italian model, while Austria, Denmark, the Netherlands, Norway and Sweden are closer to the German model (OECD, 2017 and 2018). Countries like Greece, Portugal and Spain have recently moved from a bargaining system similar to Italy's to a "controlled decentralization" which is not unlike the German system. France has long debated the desirability of a more decentralized bargaining system, and such reform was initially part of the labor market reforms proposed by President Macron in 2017, though it was subsequently dropped due to strong union opposition. While the level of macroeconomic benefit from such reforms is likely to vary from country to country depending on the extent of productivity differences across regions, it is safe to conclude that countries with binding national contracts would improve efficiency if they moved toward the German wage-setting model. Evidence on the controlled decentralization of collective bargaining in Portugal suggests that it has increased employment growth in Portugal by up to 10 percentage points (Hijzen and Martins, 2016).

This paper is part of a growing body of work that focuses on the causes and consequences of misallocation. ${ }^{9}$ The US represents an interesting specular example of spatial misallocation. In the US case, little prevents nominal wages from adjusting. ${ }^{10}$ However local employment is de facto constrained in many highly productivity cities, resulting in large spatial misallocation. Hsieh and Moretti (forthcoming) have found large efficiency losses in the form of forgone output and earnings caused by land use regulations that limit housing supply in the most productive cities, thereby constraining the flow of labor toward high-TFP locations. By contrast, in the Italian case nothing constrains local em-

\footnotetext{
${ }^{8}$ We caution, however, that the welfare implications are unknown. A welfare analysis is outside the scope of this paper, as it would require, among other things, assessing the value of leisure for currently non-employers individuals.

${ }^{9}$ Restuccia and Rogerson (2017) provides a recent survey.

${ }^{10}$ The federal minimum wage in the US is not as binding as national contracts in Europe. It only applies to low-wage workers, while European national contracts define wage floors for all levels of employment, excluding top management. Moreover, in the US there is geographic variation in minimum wages, with state- and city-level minimum wages significantly more binding than the federal minimum wage.
} 
ployment or mobility, but local wages cannot adjust to local labor demand conditions. ${ }^{11}$

Our paper is also part of the literature on centralized wage bargaining. While much research has been devoted to the effects of centralized wage bargaining, and on the estimation of wage curves in Italy, Germany and other European countries ${ }^{12}$, the combined effects of bargaining on the cost of living, real wages, the geography of employment and their aggregate costs have not previously been investigated.

The paper is organized as follows. In Section II we describe the institutional setting and wage determination mechanisms in Italy and Germany. Section III describes our theoretical model and its predictions. Section IV describes the data. Empirical evidence is presented and discussed in Section V. The aggregate costs of spatial wage rigidity are analyzed in Section VI. Section VII concludes.

\section{Wage Setting Mechanisms in Italy, Germany and Other European Countries}

We begin by describing the main features of the wage bargaining systems in Italy and Germany. We then discuss which among European countries have wage bargaining systems close to the Italian or German model. We stress that the specifics of a given country's labor market institutions are quite complex. We do not seek to provide a comprehensive description of all the features of the wage-setting systems in each European country, but instead seek to distill the key differences relevant in our analysis, abstracting from many less crucial details.

Italy. Wage bargaining institutions in Italy have been historically designed to achieve strong nominal wage compression. ${ }^{13}$ Today, national agreements between unions and employers set wages for each industry and occupational level. Industries are defined narrowly: for instance, there are currently 34 contracts in the chemical industry, 31 in textiles, and 39 in food production. Overall, there are 346 national agreements, and they cover 97.7 per cent of dependent employment in the social security system and 99.3 per

\footnotetext{
${ }^{11}$ Other authors have used similar models to measure the effect of state taxes (Fajgelbaum et al., 2015), internal trade frictions (Redding, 2013), infrastructure (Ahlfeldt et al., 2015), and land misallocation (Duranton and Puga, 2014).

${ }^{12}$ For example, Calmfors and Horn (1986), Brunello et al. (2000), Brunello et al. (2001), Boeri et al. (2001), Manacorda and Petrongolo (2001) and (Belloc et al., 2018).

${ }^{13}$ Until 1992, it was mainly the centralized indexation of wages to inflation (Scala Mobile) that reduced nominal wage dispersion across sectors, regions and skill levels. The indexation imposed the same absolute (as opposed to proportional) salary increase to all employees, independent of their salary. As a result, wage increases in percent terms were large at the bottom and small at the top of the distribution, resulting in strong compression over time as described by Erickson and Ichino (1994), Checchi and Lucifora (2002), Manacorda (2004) and Garnero (2018). This mechanism was abolished in 1992, and in 1993 the Italian government, the national trade unions, and the employer associations signed a new income policy agreement which is still in effect today.
} 
cent of firms. ${ }^{14}$

With limited exceptions, Italian firms cannot pay a salary below the level established at the national level, irrespective of their specific profitability and product demand conditions. Thus, despite large geographic differences in productivity, transportation infrastructure, geographic location, local public goods, and local government effectiveness across different areas of the country, firms in a given industry face the same wage floors. ${ }^{15}$ In theory, the system does allow for some wage bargaining at a decentralized level, either at the firm level or within local industry clusters ("distretti industriali"). In practice, decentralized bargaining is limited because it is only allowed to increase wages above the levels set by the national agreements. ${ }^{16}$

In many cases, wages in national contracts are set close to the market clearing levels in Northern regions. One reason is that Southern employers are not well represented in employer associations. Northern regions have a much larger number of firms, especially in manufacturing, and dominate the process ${ }^{17}$. Confindustria, the main employer association in manufacturing, collects almost 80 per cent of its revenues in the North and is typically led by a Northern president. ${ }^{18}$ On the workers' side, unions are less transparent on their data, but their membership also seems to be dominated by workers from Northern and Central regions. ${ }^{19}$ By contrast, Southern employers and workers do not often reach the critical mass enabling them to have a strong voice in multi-employer bargaining. Empirically, most Northern provinces are generally close to full employment in a typical non-recession year, while unemployment is invariably much higher in the South.

\footnotetext{
${ }^{14}$ By definition, national agreements do not include the informal sector.

${ }^{15}$ In some exceptional circumstances of firms facing particularly severe difficulties, wages lower than those established at the national level may be allowed. These cases are limited by "opening", "hardship" or "inability to pay" clauses to exceptional circumstances such as severe macroeconomic or idiosyncratic shocks that make downsizing unavoidable. These provisions are rarely invoked before a firm is in severe distress.

${ }^{16}$ Decentralized bargaining is limited to a small number of large firms, since the wage floors imposed by the national contracts are typically high for small and medium size firms. In a 1995-96 survey of a representative sample of 8,000 firms with at least 10 employees in both the manufacturing and service sectors, only 10 per cent of the firms reported engaging in firm-level bargaining (IStat, 2000). Since then this share has only declined (Casadio, 2003, 2008 and Brandolini et al., 2007).

${ }^{17}$ According to the Ministry of Labor 67 per cent of the registered contracts are signed in just four Northern regions (Lombardia, Emilia Romagna, Veneto and Piemonte) while only less than 10 per cent belong to agreements signed in Southern Italy

${ }^{18}$ In terms of timing, employer organizations in the four strongest regions (Lombardia, Piemonte, Veneto, and Emilia, which are all in the North) typically sign the leading contracts in metalworking, textiles, chemicals and other manufacturing sectors.

${ }^{19}$ According to Il Fatto Quotidiano of April 29, 2017, the two main unions (CGIL and CISL) have about $50 \%$ of their members in the North, only one third in the South and the rest in the Center. The third main union (UIL) is only slightly more represented in the South $(40 \%)$ because its members are mostly public sector employees.
} 
In practice, private sector Italian firms do retain a limited degree of wage flexibility. National contracts allow limited geographic differentiation and some use of merit pay. In recent years, the diffusion of "Contratti di lavoro a tempo determinato" (fixed term contracts) has allowed to pay wages below national contracts to a limited number of employees per firm ((Saggio et al., 2018)). Firms can also pay employees under the table. Thus, while one should expect wage compression, one should not expect nominal wages to be uniformly identical in the private sector. Wages in the public sector $(13.6 \%$ of employment in 2015), on the other hand, are nationally uniform; wages of teachers, doctors, nurses, social security workers, police, and military personnel are the same in every province for a given job description and level of seniority. ${ }^{20}$

Table 1 presents an actual example of an Italian wage agreement. This specific agreement applies to one occupational level ("Livello 1") in the construction sector ("Contratto Collettivo Nazionale per i Lavoratori Edili") in 2016. Entries are based on official figures released by the Italian Ministry of Labor and Social Affairs and show the degree of permitted labor cost differentiation across provinces for each specific component of labor costs. The table shows that the main components of labor costs - for example, the floor and the indexation to inflation - have no cross-province variation, while other components have limited cross-province variation. The bottom row shows that, overall, the standard deviation of total labor costs across provinces allowed by the agreement is only 0.62 euros out of a total average hourly cost of labor of almost 23 euros. In other words, the coefficient of variation is only 2.5 per cent.

Table 2 shows examples of geographic wage variations for two large private sector employers and one public sector employer. For confidentiality, we cannot reveal the names of the two private firms. The previous table referred to a wage agreement while this table reports wages actually observed in the labor market, but the picture is similar. The first row shows the median monthly salary at a large national bank. We report the median monthly salary of male bank tellers with 10 to 20 years of seniority and find limited geographic variability across North, Center and South Italy. For example, in the Northern city of Milan mean earnings are 1,659 euros per month, while in the Southern cities of Naples, Palermo and Bari they are 1,649, 1,677, and 1,670 euros, respectively. In the second row we show corresponding figures for a large national energy distribution company, inclusive of bonuses and merit pay. In both cases, we uncover limited geographic

\footnotetext{
${ }^{20}$ As a reaction to the strong nominal wage compression imposed by national agreements, the past few years witnessed an increasing number of so-called "pirate contracts" engineered by a small group of employers and a labor consultant, involving a "fake union" created ad-hoc with the purpose of signing the contract. This kind of agreement is, however, still very rare according to the National Council for Economy and Labor (CNEL, 2018).
} 
differences. If anything, wages in the energy company are slightly higher in the South, although for confidentiality reasons we cannot report wages for specific occupations. In the last row we show the salary for an elementary school teacher with 5 years of seniority. As in the rest of the public sector, there is no variation in the nominal wage across areas. ${ }^{21}$

These are motivating examples based on three specific cases. In Section V we will present more systematic evidence on geographic wage heterogeneity for a representative sample of Italian workers based on labor survey data.

Germany. Germany offers an interesting case study to compare with Italy. Before the Unification of East and West Germany, the country had a wage-setting system not unlike Italy's today. The system was changed after Unification due to the large differences in productivity levels between East and West and the many firms' threats to walk out of employer associations. In particular, "opening clauses" were enhanced to allow firm-level bargaining for wages lower than those established at the national level (see Dustmann et al. (2014) for a discussion of German labor market institutions and their reforms). Opening clauses enable company management and works council to conclude works agreements which deviate from the industry-level collective agreement within certain limits. In the chemical industry, for instance, an opening clause allows companies to reduce the collectively agreed wage by up to 10 percent for a limited period of time in order to save jobs or improve competitiveness. ${ }^{22}$

More precisely, until the mid-1990s the German system was based on a two-tier bargaining structure. First, industry-wide collective bargaining negotiations between unions and employer associations in the private sector (with the exception of the construction sector) took place at the regional ("Lander") level. One of the regions was typically pivotal for negotiations in other regions. Then plant-level bargaining took place, but wages could only increase relative to those established at the regional level. Since collective agreements were often settled uniformly for the whole industry (with only minor regional differences), wage differentiation between regions, sectors, and plants was only achievable if plants paid premiums above the contract wage (Schnabel, 1998, Dustmann et al., 2009).

After German unification, the scope for plant-level bargaining was significantly enhanced by extending the scope for opting-out and derogation clauses from the wage

\footnotetext{
${ }^{21}$ The 2018 Minister of Education has tried to introduce pay differentials among teachers in an attempt to fill outstanding vacancies in Northern schools, while there are no vacancies in Southern schools.

${ }^{22}$ Trade unions and employer associations retain the right to veto such deviating works agreements. Sectoral agreements also impose a number of conditions for derogations to apply: companies have to disclose their financial information allowing workers representatives to have enough time to scrutinize the financial status of the firm, and the derogation must be temporary.
} 
floors established by higher levels of bargaining. This development was caused by the concern that employers in the new Eastern regions might leave their respective associations in order to separately negotiate their labor contracts. The threat of large-scale association downsizing if less-productive firms in the East had to adopt Western wage floors was a factor in generating union support for "opening clauses". Another threat was the possible relocation of firms to neighboring Eastern European countries.

The decline in the importance of collective bargaining and the rise of opening clauses is quantified in Table 3. The ultimate effect of this reform was a significant increase in the decentralization of wage-setting in Germany. ${ }^{23}$ The decline in the importance of industrylevel contracts in Germany after 1995 and the corresponding increase in the importance of firm-level wage-setting mechanisms have allowed a growing number of German firms to set wages in line with their productivity.

Other countries. An analysis of the Italian and German bargaining systems has implications not just for Italy and Germany, but also for other countries. While the specifics of each country labor market institutions are different, key aspects of the Italian and the German bargaining systems are present elsewhere.

For our purposes, the key difference between the Italian and German systems is that the latter permits a much wider scope for decentralized bargaining than the former, allowing wages to vary more as a function of local productivity. Within the OECD, countries with systems closer to Germany's tend to leave considerable room for firm-level bargaining and/or permit deviations or opt-outs from sectoral agreements under a broad set of circumstances. OECD (2018b) calls this system "organized decentralization". According to the OECD, the group of countries that had a system of organized decentralization in 2015 includes Austria, Denmark, the Netherlands, Norway, and Sweden along with Germany (OECD, 2018b).

By contrast, countries with systems closer to Italy's are countries where national industry level agreements play a dominant role and deviations are either not possible or only allowed for wage increases relative to sectoral agreements. ${ }^{24}$ According to the OECD,

\footnotetext{
${ }^{23}$ The higher fraction of workers subject to opening clauses in the West, displayed in Table 3, may come as a surprise since theory would predict a larger need for deviations from the sectoral contracts for Eastern firms. However, it should be noted that opening clauses do not only allow deviations in terms of wages, but also for example working hours, flexibility of overtime arrangements, reductions of constraints to workers mobility within the firm and between jobs and tasks. These types of opening clauses have been relatively common since the mid 1980s (Kohaut and Schnabel, 2007) and are frequent in the West on average. However, Brändle et al. (2011) shows that the share among all opening clauses that deal with wage setting has increased dramatically since the mid-90s. The time trend displayed in Table 3 clearly shows that this increase in the use of opening clauses is more pronounced in the East.

${ }^{24}$ Sometimes this principle extends beyond pay and includes employment features like hours and annual
} 
this group includes France, Iceland, Portugal, and Slovenia (OECD, 2018b).

In the wake of the Euro-area crisis, three countries - Spain, Portugal, and (to some extent) Greece -recently transitioned from a highly-centralized system towards a more decentralized, German-style model. A comparison of the Italian and German system can be informative on the possible effects of these reforms.

More generally, many European countries have a two-tier bargaining structure in which sector-level bargaining can, in principle, be accompanied by plant-level or local area bargaining. For example, in Denmark the proportion of firms carrying out two-tier bargaining more than doubled between 1989 to 1995 (Traxler et al., 2001; Andersen et al., 2003). Similarly, the number of Belgian firms involved in both industry and plant-level agreements increased tenfold from 1980 and the mid-1990s (Van Ruysseveldt and Visser, 1996). Two-tier bargaining structures are also present in Austria, Finland, the Netherlands, Norway, and Sweden (Boeri et al., 2001).

\section{Theoretical Framework}

Both Italy and Germany have large spatial productivity differences. In Italy, national contracts limit the ability of local wages to adjust to local productivity, while in Germany the past two decades of labor market reforms have allowed employers to adjust wages to local productivity.

In this section, we present a simplified spatial equilibrium model intended to provide intuition for the effects of the Italian and German wage-setting systems and to guide our empirical analysis. The model is a standard Rosen-Roback model and is kept deliberately simple. The main objective is to compare the spatial equilibria under two extreme cases: (1) local nominal wages can freely adjust to local productivity, and (2) local nominal wages cannot adjust (due to institutional constraints) but workers and firms are free to relocate. Rosen-Roback models of spatial equilibria have traditionally focused on the case of market clearing. The case where the labor market does not clear has not received much attention. ${ }^{25}$

In interpreting the model, two points need to be clear. First, while the model provides useful benchmarks, it should be clear that neither Germany nor Italy is exactly described by either of these two extremes. While German firms have some flexibility to set nominal wages more in line with local productivity levels, union contracts ensure that this flexibility is not absolute. Similarly, while Italian firms have less flexibility in setting nominal wages, they nevertheless maintain some ability to adjust wages. Second, the focus is on

leave, which firms can only improve upon from the perspective of employees.

${ }^{25}$ Kline and Moretti (2013) model a case where unemployment arises from search frictions. 
geographic differences. Thus, we abstract from labor market institutions that are uniform across the country, such as employment protection and unemployment benefits. While both Germany and Italy have important labor market rigidities of this variety, their effects are clearly outside the scope of this paper.

\section{III.A Setup}

We consider two regions $r=\{n, s\}$ that produce a traded good with a price set on the international market. Production in each region is given by:

$$
Y_{r}=A_{r} K_{r}^{(1-\alpha)} E_{r}^{\alpha}
$$

where $A_{r}$ denotes Total Factor Productivity (TFP); $E_{r}$ is employment and $K_{r}$ is capital. The two regions are ex-ante identical with the exception of their level of TFP. We assume that $n$ is more productive than $s$ due to exogenous historical factors: $A_{n} \geq A_{s}$.

Population of each region is $L_{r}$, with the total population of the country $\bar{L}=L_{n}+L_{s}$ assumed fixed. The utility of a resident of region $r$ is given by:

$$
\Omega_{r}=\frac{w_{r}}{p_{r}^{\sigma}}\left(1-u_{r}\right)^{\delta}
$$

where $w_{r}$ is the nominal wage level, $p_{r}$ is the housing price in region $r ; \sigma$ is the weight of housing in the consumption basket; $u_{r}$ is the non-employment rate in region $r: u_{r}=$ $1-\left(E_{r} / L_{r}\right) .{ }^{26}$ We assume that workers can freely move across regions and that they optimally choose where to live. Specifically, we assume zero mobility costs and no heterogeneity in taste for location. Thus, in equilibrium it needs to be the case that workers are indifferent across the two regions: $\Omega_{n}=\Omega_{s} .{ }^{27}$

Firms optimally choose how many workers to hire and how much capital to use. As in the standard model, factor demand comes from the first order conditions implying that the price of each factor must be equal to its marginal product. Capital is supplied to firms in a region at an increasing price: $i_{r}=\mu \ln K_{r}{ }^{28}$

To close the model, we assume that each resident consumes one unit of housing and that the supply of housing is upward sloping: $\ln p_{r}=\gamma \ln L_{r}$. Put differently, housing costs are proportional to regional population.

\footnotetext{
${ }^{26}$ For simplicity, we ignore local amenities and assume that workers are renters. Both assumptions can be relaxed.

${ }^{27}$ In the case of heterogeneity in taste for location, the marginal worker is indifferent between the two locations, so results are qualitatively similar (see Moretti, 2011).

${ }^{28}$ This is another easily alterable assumption. We need to have at least one scarce factor (it could be land if not capital) in order to obtain a downward sloping labor demand in each region.
} 
Nominal wages, employment, capital, housing prices, population, and interest rates in each of the two regions $-w_{n}, w_{s}, E_{n}, E_{s}, K_{n}, K_{s}, p_{n}, p_{s}, L_{n}, L_{s}, i_{n}, i_{s}-$ are endogenous.

\section{III.B Equilibrium When Wages Are Set by Market.}

We first consider the standard free market case with flexible wages. The usual condition that a region's nominal wage equals the region's marginal product of labor follows from firms' first order conditions:

$$
w_{r}^{*}=\alpha A_{r} K_{r}^{*(1-\alpha)} E_{r}^{*-(1-\alpha)}
$$

where the asterisk denotes an equilibrium variable in the free market case. Similarly, demand for capital in the two regions is determined by the marginal product of capital, obtained by differentiating Equation 1 with respect to $K$. In equilibrium, the marginal product of capital equals the rate of return. Given the additional condition that workers must be indifferent between the two regions, employment, population, capital and housing prices in the two regions are determined. The resulting equilibrium is the standard Rosen-Roback equilibrium, which is well understood in the literature. For our purposes, three features of this equilibrium are worth emphasizing.

First, equilibrium employment, capital and nominal wages are higher in $n$, which is the region with higher TFP. This can be seen explicitly by expressing equilibrium employment, capital and nominal wages as a function of the model exogenous parameters:

$$
\ln E_{n}^{*}-\ln E_{s}^{*}=\frac{(1+\mu)}{\sigma \gamma(\mu+\alpha)+\mu(1-\alpha)}\left(\ln A_{n}-\ln A_{s}\right)>0
$$

$$
\ln K_{n}^{*}-\ln K_{s}^{*}=\frac{(1+\sigma \gamma)}{\sigma \gamma(\mu+\alpha)+\mu(1-\alpha)}\left(\ln A_{n}-\ln A_{s}\right)>0
$$

$$
\ln w_{n}^{*}-\ln w_{s}^{*}=\frac{(1+\mu) \sigma \gamma}{\sigma \gamma(\mu+\alpha)+\mu(1-\alpha)}\left(\ln A_{n}-\ln A_{s}\right)>0
$$

These three equations make intuitive sense. Since TFP is higher in $n$, profit-maximizing firms hire more workers and use more capital in that region. The differences in labor and capital inputs are proportional to the difference in TFP. The marginal product of labor is also higher in $n$, and hence the equilibrium nominal wage is higher, with the regional 
wage gap proportional to the gap in TFP.

Housing costs are higher in $n$ because more workers live there in equilibrium:

$$
\ln p_{n}^{*}-\ln p_{s}^{*}=\frac{(1+\mu) \gamma}{\sigma \gamma(\mu+\alpha)+\mu(1-\alpha)}\left(\ln A_{n}-\ln A_{s}\right)>0
$$

The difference in housing costs between the North and the South needs to be large enough to make workers indifferent between the two regions. This follows from the spatial equilibrium assumption. As a result, while nominal wages are higher in $n$ in equilibrium, real wages are equalized in the two regions:

$$
\frac{w_{n}^{*}}{p_{n}^{* \sigma}}=\frac{w_{s}^{*}}{p_{s}^{* \sigma}}
$$

Finally, there is full employment in both regions, since there are no rigidities preventing the labor market to clear: $u_{n}^{*}=u_{s}^{*}=0$.

\section{III.C Equilibrium When Wages Are Set by National Contract.}

We now turn to the case of wage rigidity due to collective bargaining. We assume that a national contract forces firms to pay the same nominal wage $\bar{w}$ in the two regions despite productivity differences. In particular, we focus for simplicity on the case where nominal wages are set equal to the market clearing wage in $n$, and thus above the market clearing wage in $s$ :

$$
\bar{w}=w_{n}^{*}>w_{s}^{*}
$$

As discussed in Section II, this is consistent with the typical prescription of a union contract in Italy. Results are qualitatively similar when nominal wages are set between the market clearing wage in $n$ and $s: w_{n}^{*}>\bar{w}>w_{s}^{*}$.

After $\bar{w}$ is set by the national contract, employment, population, and housing prices adjust endogenously in the two regions. Non-employment also adjusts endogenously, since it depends on employment and population. The key difference relative to the free market case is that a national contract results in lower equilibrium employment, capital and output in $s$. While the wage in $s$ is higher relative to the free market equilibrium, fewer workers are employed and total national employment declines. As a consequence, aggregate output and aggregate earnings are lower. By imposing a wage in $s$ that exceeds s's productivity, the national contract generates spatial misallocation and causes a 
national economic loss.

To see this in more detail, consider how firms set employment in this context. The right-hand side of Equation (2) still represents the region's marginal product of labor, and therefore the labor demand function of firms in that region. But now the region's nominal wage is not endogenously determined by the market. Instead, it is exogenously set equal to $\bar{w}$. Firms in each region maximize profits by choosing employment and capital accordingly. It's clear that firms in $s$ will hire fewer workers, simply because labor demand is downward sloping.

Just like in the free market case, residents reallocate between $n$ and $s$ until utility is equalized in the two regions. Thus in equilibrium:

$$
\frac{\bar{w}\left(1-u_{n}^{* *}\right)}{p_{n}^{* * \sigma}}=\frac{\bar{w}\left(1-u_{s}^{* *}\right)}{p_{s}^{* * \sigma}}
$$

where the double asterisk denotes an equilibrium variable in the collective bargaining case. A number of important features of this equilibrium are worth discussing. First, employment is lower in s. A comparison with Equation (3) indicates that the employment gap is larger than in the free market case:

$$
\ln E_{n}^{* *}-\ln E_{s}^{* *}=\frac{(1+\mu)}{\mu(1-\alpha)}\left(\ln A_{n}-\ln A_{s}\right)>0
$$

Unlike in the free market case, now $s$ experiences equilibrium non-employment: $u_{s}^{* *}>0$. Intuitively, $\bar{w}$ is above the market clearing wage in $s$ and non-employment results from the wedge between the wage and local productivity. In equilibrium, the level of nonemployment in $\mathrm{s}$ is proportional to the productivity gap:

$$
u_{s}^{* *}=\frac{(1+\mu) \sigma \gamma}{\mu(1-\alpha)(\sigma \gamma+\delta)}\left(\ln A_{n}-\ln A_{s}\right)>0
$$

By contrast, $n$ enjoys full employment because $\bar{w}$ is assumed to be equal to its market clearing wage.

As in the free market case, housing costs are higher in $n$ since employment and population are higher there, ${ }^{29}$ but unlike the free market case, real wages are now lower in $n$ :

$$
\frac{\bar{w}}{p_{n}^{* * \sigma}}-\frac{\bar{w}}{p_{s}^{* * \sigma}}=-\frac{(1+\mu) \sigma \delta \gamma}{\mu(1-\alpha)(\sigma \gamma+\delta)}\left(\ln A_{n}-\ln A_{s}\right)<0
$$

\footnotetext{
${ }^{29}$ In particular: $\ln p_{n}^{* *}-\ln p_{s}^{* *}=\frac{(1+\mu) \delta \gamma}{\mu(1-\alpha)(\sigma \gamma+\delta)}\left(\ln A_{n}-\ln A_{s}\right)>0$.
} 
Intuitively, this is due to the fact that housing costs are lower in $s$ but nominal wages are the same. This has the interesting implication that conditional on employment ${ }^{30}$, residents of $s$ are better off than residents of $n$. Specifically, residents of $s$ queue to get a job and those who earn jobs are better off than their counterparts in $n$.

Finally, in equilibrium firms invest less in $s$ than in $n .{ }^{31}$

\section{III.D Aggregate Effects}

We have found that in the fixed wage equilibrium, a fraction of residents in $s$ are not employed. They optimally choose to stay in $s$ even if they are idle because if they were to find a job, the real wage would be higher. Therefore, relative to the free market equilibrium, the fixed wage equilibrium results in lower aggregate employment in the country. Moreover, since capital and labor are imperfect substitutes, the total stock of capital in $s$ is also lower in the fixed wage equilibrium. ${ }^{32}$ Thus, the fixed wage equilibrium results in lower aggregate output: $Y_{n}^{*}+Y_{s}^{*}>Y_{n}^{* *}+Y_{s}^{* *} .33$

If labor demand is elastic, the fixed wage equilibrium also results in lower labor income

$$
\frac{\left(w_{n}^{*} E_{n}^{*}\right)+\left(w_{s}^{*} E_{s}^{*}\right)}{\bar{L}}>\frac{\left(\bar{w} E_{n}^{* *}\right)+\left(\bar{w} E_{s}^{* *}\right)}{\bar{L}}
$$

To see why, notice that we can rewrite this inequality as

$$
\left(\bar{L} u_{s}^{* *}\right) \bar{w}>E_{s}^{*}\left(\bar{w}-w_{s}^{*}\right)
$$

This expression can be seen graphically in Figure 1, which shows the marginal product of labor (and therefore the labor demand) in $s$. Points 1 and 2 are the free market equilibrium and the fixed wage equilibrium, respectively. The left-hand side of Equation 12 is the area of the rectangles $A+C$. The right-hand side is the area of the rectangles $B+$ C. Labor income is larger under free market if $\mathrm{A}$ is larger than B. ${ }^{34}$

\footnotetext{
${ }^{30}$ For simplicity we do not consider non-employment benefits, such as welfare payments, which would require introducing a government budget constraint. Insofar as welfare payments are not indexed to the local cost of living (as in Italy), their inclusion in the model would not alter other qualitative results.

${ }^{31}$ The gap in the capital stock is $\ln K_{n}^{* *}-\ln K_{s}^{* *}=\frac{1}{\mu(1-\alpha)}\left(\ln A_{n}-\ln A_{s}\right)>0$.

${ }^{32}$ The equilibrium amount of capital in $s$ is $\ln K_{s}^{* *}=\frac{\ln A_{s}+\ln (1-\alpha)+\alpha \ln E_{s}^{* *}}{\mu+\alpha}$. Since $E_{s}^{* *}<E_{s}^{*}$, it follows that $K_{s}^{* *}<K_{s}^{*}$.

${ }^{33}$ Note that employment and capital are higher in $n$ in the fixed wage equilibrium compared to free market equilibrium. But this only partially mitigates the aggregate losses.

${ }^{34}$ The term $\left(\bar{L} u_{s}^{* *}\right)$ on the left-hand side is the total number of non-employed. The employment loss $\left(\bar{L} u_{s}^{* *}\right) \bar{w}$ is smaller than the change in employment in $s$ because under fixed wages employment in $n$ is higher than under free market.
} 
Intuitively, setting the wage above the market wage in $s$ has two effects. On the one hand it raises the wage that employed workers receive by $\left(\bar{w}-w_{s}^{*}\right)$. On the other it lower employment by an amount defined in Equation (9). Labor income declines relative to the free market case if labor demand is sufficiently elastic, as represented in the Figure. For a small open economy, product demand and therefore labor demand are likely to be elastic.

Overall, the wage rigidity created by national union contracts has aggregate costs in terms of forgone aggregate employment, output and possibly labor income. In Section VI we will quantify these losses in the case of Italy.

\section{Data}

Our empirical analysis is based on data for the labor and housing markets in Italy and Germany. Employment rates are obtained by the national statistical offices and are for individuals aged 15-64. Our wage data for Italy and Germany are from the National Italian Statistical Office (ISTAT) quarterly labor force statistics ${ }^{35}$ and the Institute for Employment Research $(\mathrm{IAB})^{36}$, respectively. They include all private and public employees for Italy (individual-level wage data for 2009 - 2013); and all private and public employees who are subject to social security contributions for Germany (individual-level wages for 1992 - 2014). In both countries wages are defined on a monthly basis excluding all non recurrent additional components of pay. Either in Italy and Germany we focus on full-time workers, and obtain hourly or daily wages by dividing monthly wages on the basis of the reported average weekly hours and days of work. For Italy, housing cost information comes from the Osservatorio Mobiliare Italiano and contains transaction-level data on residential real estate sales in Italy between 2004 and 2011. The dataset also contains information about the characteristics of the individual unit and the municipalities (or urban area) in which it is located. German housing data are obtained from the Federal Institute for Research on Building, Urban Affairs and Spatial Development (BBSR), which is the regional planning authority in Germany. They provide aggregate data on rental prices observed in Germany for the years 2004-2014 as posted online or on newspaper advertisements, controlling for key characteristics such as flat size and whether or not it is furnished.

Data on gross value added for all industries are from OECD (2018a).

Geographical Unit of Analysis. Choosing a geographic definition of local labor mar-

\footnotetext{
${ }^{35}$ The surveys cover about 600,000 individuals. Wage information is provided only since 2009 by the Italian Labor Force Survey. In this study we focus on the period 2009-13.

${ }^{36}$ This study uses the factually anonymous Sample of Integrated Labour Market Biographies (version 1975 - 2014). Data access was provided via a Scientific Use File supplied by the Research Data Centre (FDZ) of the German Federal Employment Agency (BA) at the Institute for Employment Research (IAB).
} 
kets constitutes an important assumption in our study. Ideally, we would like to use a geographic unit akin to US Metropolitan Statistical Areas or Commuting Zones, which are small enough to encompass economically-meaningful units but large enough that most residents both live and work within a single region. Administrative boundaries of municipalities are likely to be too small; Italian and German workers easily commute across municipalities. For Italy, our definition of local labor markets is based on 103 provinces, with average working-age population of 495,104 . The minimum and maximum workingage population are 76,884 to 3,418,941. For Germany, we base our definition on 96 "Spatial Planning Regions" (Raumordnungsregion) with an average working age population of 737,448 and a range of 187,990 to 3,030,240.

In Italy, we define North and South by including in the North the following regions: Emilia-Romagna, Friuli Venezia Giulia, Liguria, Lombardia, Marche, Piemonte, Toscana, Trentino-Alto Adige, Umbria, Valle d'Aosta, Veneto. The South is everything else. In Germany, we define West and East based on the historical Cold War division, with Berlin assigned to East.

Wages, Employment and Informal Sector. We seek to measure mean wages by province and year in Italy and Germany, controlling for differences in worker quality and industry mix across provinces. To estimate conditional average wages net of workers' characteristics and industry effects, we use worker-level data for Italy and Germany to regress

$$
w_{i}=\alpha+Z_{i} \beta+u_{i}
$$

where $w_{i}$ is the hourly (Italy) or daily (Germany) wage of worker $i$ and $Z_{i}$ is a vector that includes worker $i$ 's gender, age, age squared, education, and industry. The regression is performed separately for Italy and Germany. We take the average residual $\hat{u}_{i}$ for every province-year pair, which we interpret as the average wage in that province and year holding constant worker observable characteristics and industry. ${ }^{37}$ In the remainder of the paper, the term "wages" will refer to conditional mean wages.

In measuring employment in Italy, a potentially important issue is the existence of a large informal sector, which includes workers paid under the table to avoid taxes and Social Security contributions. Since the informal sector is widely understood to be larger

\footnotetext{
${ }^{37}$ To scale the average wage properly, we add to each province-year mean residual the mean national wage in 2010. This re-scaling simply means that our measures of conditional wages for Italy and Germany are scaled so that their averages equal the 2010 average wage in Italy and Germany, respectively. Due to data availability, for Italy, we use hourly wages net of taxes, while for Germany we use daily wages gross of taxes. We will present robustness checks to assess whether using wages net or gross of taxes in the two countries matters for our results.
} 
in Southern provinces than in Northern provinces, this has the potential to lead us to underestimate employment rates in the South. Two points are worth noting. First, the employment rates that we use are computed using data that come from Istat Quarterly Labor Force Survey which is anonymous. In contrast to employment rates obtained from Social Security records, which are based on earnings reported by employers to the government and therefore miss the informal sector by construction, workers in the sample that we use to compute our employment rates have limited incentive to misreport their employment status. Second, we will present additional estimates that are based on corrected employment rates, obtained by adding to our baseline employment rates estimates of informal employment by province produced by the Italian National Statistical Institute (Istat, 2014).

Housing Costs and Local Cost of Living Indexes. We seek to measure mean cost of housing by province and year, controlling for differences in housing quality across provinces. For Italy, we follow the same approach that we use for wages. We regress

$$
p_{i}=\alpha+X_{i} \beta+u_{i}
$$

where $p_{i}$ is the price per square meter of housing unit $i$ and $X_{i}$ is a vector that includes unit size, presence of a balcony, terrace or cellar, brightness, views, orientation, measures of quality of construction, distance to retail stores, distance to public transport, distance to public park or garden, parking, indicators for neighborhood type, and whether the municipality is located by the sea or in the mountains (these last two variables come from ISTAT). As with the wage residuals above, we then average the residuals from this regression by year and province.

The German housing data are rent prices collected by the regional planning authority BBSR from online or newspaper advertisements. To compute prices per square meter, the BBSR uses non-furnished flats of a size between 40 and 130 sqm in announcements listed for less than half a year. They filter out implausible prices and luxury flats. We compute weighted averages by Raumordnungsregion, using weights that reflect the stock of housing in the area.

The main source of geographical differences in local cost of living is represented by differences in cost of housing. An additional source is represented by differences in the price of non-tradable goods and services. The price of non-tradables tends to vary regionally with the price of housing. For example, a sandwich or haircut in Milan tend to cost more than a sandwich or haircut in Palermo. We build a local Consumer Price Index (Local CPI) following the methodology proposed by Moretti (2013) and using data on 
regional measures of CPI from the Italian and German statistical offices. ${ }^{38}$

Productivity. To our knowledge, the only measure of firm productivity available at a fine geographic level in Italy and Germany is gross value added. Gross value added is firm output valued at basic prices less intermediate inputs valued at purchaser prices. The basic price is the amount receivable by the producer from the purchaser for a unit of a product or service minus any tax on the product plus any subsidy on the product. Gross value added per worker in each province is obtained by dividing this measure by employment in that province. We obtain data on gross value added per worker for all industries at the local level from $\operatorname{OECD}(2018 \mathrm{a})$.

Table A-1 shows summary statistics for 2010. Unsurprisingly, the non-employment rate is on average higher in Italy (42.5\%) that in Germany $(27.9 \%)$. This remains true when the Italian figure is corrected for the existence of informal work $(34.0 \%)$. When considering mean wages, it should be noted that in our data wages are defined as hourly wages for Italy and daily wages for Germany. Mean value added per worker is slightly higher in Italy than in Germany. This likely reflects the fact that the available variable does not account for hours worked, which are not available at the detailed local level at which we run our analysis. Since the fraction of part time workers is on average higher in Germany (26.3\%) than in Italy (15\%), even if hourly value added is higher in Germany, value added per worker is higher in Italy. We do not expect this to be a major problem for our analysis, since we focus on differences between provinces within each of the two countries. $^{39}$

\footnotetext{
${ }^{38}$ Both countries' statistical offices provide regional measures of CPI that cannot be used for geographic comparisons as they are normalized to 1 in a given year. Nevertheless, they can be used in quantifying the relationship between prices of housing in an area and the price of other goods and services in that area. Specifically, we regress changes over time in CPI for a province on changes of its housing component. We run these regressions separately for Italy and Germany. Using these estimates, we then construct a Local CPI for Italy and one for Germany. The two Local CPI's measure differences in cost of living across provinces within each of the two countries. Local $C P I_{p t}$ is defined as $C P I_{p t}=\omega H P_{p t}+(1-\omega) N H P_{p t}$ where $H P_{p t}$ is housing price in province $p$ and year $t, N H P_{p t}$ is the price of non-housing or non-tradables, and $(\omega)$ is the housing weight. Some part of NHP varies with the housing price so that $N H P=\pi H P+v$. Therefore when we regress $\triangle C P I_{p t}$ on $\Delta H P_{p t}, \beta=(\omega+(1-\omega) \pi)$. Then, we use $\omega$ to compute: $\pi=\frac{\beta-\omega_{n}}{1-\omega_{n}}$. We then use the province specific housing prices obtained through our own calculations and construct the local CPI as:

$$
C P I_{p t}=\omega H P_{p t}+(1-\omega)\left[\pi H P_{p t}+(1-\pi) N H P_{t}\right]
$$

(see Moretti (2013) for details). The housing weight in consumption $\omega$ for Germany is obtained from the German Federal Statistical Office (Destatis). For Italy we use consumption weights from households consumption surveys for the years 2005-2011. See also Jappelli and Pistaferri (2000).

${ }^{39}$ More productive regions tend to have a higher share of part-time employment in both countries, but the dispersion of the fraction of part-time workers across local areas is similar in Germany and Italy, ranging, in 2010 , between $20.2 \%$ and $32.1 \%$ among the 16 German regions and between $10.6 \%$ and $20.5 \%$ among the 20 Italian regions. If we regress the log part-time share per region on the log value added per worker of
} 


\section{Empirical Evidence}

In this section, we first document the degree of productivity differences across provinces in Italy and Germany (subsection V.A). We then turn to wages, studying the relationship between nominal wages and local productivity (subsection V.B). Third, we study the relationship between non-employment rates and local productivity (subsection V.C) and the relationship between real wages and local productivity (subsection V.D).

\section{V.A Value Added}

The maps in the top part of Figure 2 show value added per worker in Italy (left panel) and Germany (right panel) in 2010. Throughout the paper, all maps are in percent deviations from the unweighted national mean. The bottom part in Figure 2 shows the spatial distribution of value added in the two countries across provinces in 2010.

Two features are important. First, the overall amount of geographical variation in productivity is similar in Italy and Germany, with the bulk of the distribution between -20\% and $20 \%$ in both countries. ${ }^{40}$ This level of geographic variation is not atypical among industrialized countries and it is not unlike what we see, for example, in the US (Hornbeck and Moretti, 2018).

Second, while there is some overlap, it is clear from the Figure that in Italy Northern provinces are vastly more productive than Southern provinces, and in Germany Western provinces are similarly more productive than Eastern provinces. Interestingly, the patterns are comparable in the two countries: the difference between the mean province in Northern and Southern Italy is $17.6 \%$, while the difference between the mean province in West and East Germany is $22.7 \%$.

We stress that in this paper, we take these differences as given; our analysis focuses on the effects of these differences rather than their causes. As we discuss above, in Italy, North-South differences probably reflect historical differences in many determinants of regional productivity, including transportation infrastructure, distance from European markets, efficiency of local governments and local policies, criminal activity, and cultural norms. These differences are long lasting and largely determined by historical factors. In Germany, East-West differences likely reflect half a century of Communist rule in the East as well as other historical factors. While it is in principle possible to model endogenous

each region including year fixed effects (years 2005-2014). The coefficient of this regression in Germany is 0.60 while for Italy it is 0.69 . This implies that the relationship between value added and part-time work across provinces is very similar in the two countries and that the incidence of part-time work is not likely to bias our results.

${ }^{40}$ The range $90-10$ percentile difference and $75-25$ percentile difference are: $57.79 \%, 27.92 \%$ and $17.95 \%$ in Italy and $70.47 .72 \%, 39.92 \%$ and $17.65 \%$ in Germany. 
regional differences in the long run, such models are outside the scope of this paper.

\section{V.B Nominal Wages}

The map in the top part of Figure 3 shows geographical differences in nominal wages in the two countries, drawn using the same scale. The difference between Italy and Germany is seen even more clearly in the bottom part of Figure 3, which shows the spatial distribution across provinces in the two countries.

The distribution is more compressed in Italy than in Germany, as one might expect based on the wage bargaining systems in the two countries. The mass of the distribution in Italy is between $-10 \%$ and $10 \%$ of the country mean, while in Germany it is between $-26 \%$ and $22 \%$. The $75-25$ percentile difference and $90-10$ percentile difference were $5.8 \%$ and $10.3 \%$ in Italy and $13.1 \%$ and $42.9 \%$ in Germany. The amount of spatial wage dispersion in Germany is lower than what we see in the US, but not by much (Dauth et al., 2018). By contrast, the amount of spatial wage dispersion in Italy is much lower.

Wages are by no means completely uniform across Italian provinces, despite national wage contracts at the industry level, for the reasons discussed in Section II. Moreover, there are data limitations. National contracts specify a given wage for a given occupation and level of seniority in the firm. While we control for a worker work experience, as standard in wage regressions, we do not directly observe seniority. Our occupational categories are not as fine as those used in union contracts. There may also be measurement error in our data. While we use the largest available dataset, sample sizes in each province are finite.

Overall, while there is some geographical wage dispersion in Italy, it is clear from Figure 3 that wage dispersion is significantly wider in Germany. For our purposes, the empirical relationship between local productivity and local nominal wages is particularly important. If wages can fully adjust, our model indicates that we should see a tight relationship between the two, with provinces that enjoy higher productivity having higher nominal wages. This is indeed the case in the US (Hornbeck and Moretti, 2018). By contrast, if wages are prevented from fully adjusting, we should see a weaker relationship or none at all.

Figure 4 presents scatter plots that document the relation between the log conditional mean nominal wage by province on the $y$-axis and log mean value added on the $x$-axis in 2010. The Figure shows that while in Germany there is a positive relationship between local nominal wages and local productivity, in Italy the relationship is significantly weaker. Thus, German firms appear significantly more able to adjust nominal wages to local productivity than Italian firms. Indeed, the graph for Italy suggests almost no relationship 
between wages and productivity, presumably due to constraint imposed by nationwide contracts.

Table 4 shows the corresponding regression coefficients. ${ }^{41}$ Columns 1 and 3 indicate that in a regression of log conditional mean nominal wage on log mean value added the elasticity of nominal wages with respect to local value added is 0.19 and 0.73 in Italy and Germany, respectively. In other words, the elasticity is almost four times larger in Germany than in Italy. In columns 2 and 4 we condition on region fixed effects, where regions are North and South in Italy, and East and West in Germany. These models absorb North-South and East-West differences in the determinants of wages, and are identified by variation in value added within a region. In these models, the elasticity for Italy drops to 0.13 , while in Germany is 0.37 , or three times larger. ${ }^{42}$

Overall, we find that despite large productivity differences across provinces, Italy's wage-setting mechanism results in nominal wages that are generally compressed across space. Crucially, there is little or no correlation between mean productivity in a province and mean nominal wages. By contrast, Germany has more nominal wage dispersion. Although Germany has the same amount of productivity difference across provinces, the absence of binding national wage contracts allows wages to better adjust to local labor market conditions.

\section{V.C Probability of Non-Employment and Informal Employment}

Our model predicts that in Italy, where wages cannot adjust fully, provinces with low productivity should have higher non-employment rates. This should be less true in Germany, where wages can adjust more to local productivity.

The maps in the top part of Figure 5 show rates of non-employment in Italy and Germany, by province. This difference between the two countries is more clear in the bottom part of Figure 5, which shows the spatial distribution of non-employment rates in the two countries. In Italy there is almost no overlap between the North and the South in non-employment rates. While the North is at or close to full employment, the South has much higher rates of non-employment. Germany is different. Despite equally large spatial productivity differences, the East-West differences in non-employment rates are much smaller. Indeed, the distributions for West Germany and East Germany overlap almost

\footnotetext{
${ }^{41}$ The sample includes years 2000-2014 for Germany and 2009-2013 for Italy.

${ }^{42} \mathrm{~A}$ similar point is made in Appendix Table A-2. In the first row, we regress individual level log wages on workers characteristics: sex, age, age squared, education and industry. Entries in the table refer to the $R^{2}$. In the second row, we add province fixed effects. In Italy, the $R^{2}$ increases only marginally, from 0.35 to 0.36 . By contrast, in Germany the $R^{2}$ increases significantly more, from 0.39 to 0.46 . This suggests that despite large productivity differences across provinces, local factors play a minimal role in explaining individual level wage variation in Italy, and a larger role in Germany.
} 
completely.

Figure 6 shows more explicitly the relation between non-employment rate and log mean value added in 2010. Unsurprisingly, the elasticity of non-employment with respect to value added appears negative in both countries, indicating that provinces with lower value added have higher non-employment. But it is clear that the elasticity is significantly more negative for Italy than Germany. In Italy, areas with low mean value added have much higher non-employment rates than areas with high mean value added; in Germany, where nominal wages can adjust to local value added, the difference in non-employment rates is significantly smaller.

Column 1 and 5 in Table 5 show the corresponding regression coefficients. The elasticity in Italy is -1.43 , almost six times larger in absolute value than the elasticity in Germany. In columns 2 and 6 we show estimates from models that include region fixed effects. These models controls for North-South and East-West differences in factors that affect non-employment rates, and are identified by variation in value added within each region. Both elasticities drop significantly, but the one for Italy remains 5 times larger than the one for Germany.

In interpreting Table 5 (and similar regression tables below), one concern is the possibility that the reported coefficients are biased by the presence of omitted variables. Provinces within Italy and Germany differ in many respects, including infrastructures, efficiency of the public administration, crime rates, distance to European markets, etc. For the coefficients in Table 5 to be unbiased it needs to be the case that these differences affect non-employment only through differences in mean value added per worker. For example, if Southern Italian provinces have worse transportation infrastructure than Northern Italian provinces, or they are further away from European markets, the estimated coefficients are unbiased if these differences in infrastructure and market distance are fully reflected in lower value added per worker in Southern provinces compared to Northern provinces. Put differently, the regression coefficients in Table 5 are unbiased if conditional on local mean value added, there is no additional direct effect of quality of transportation infrastructure or distance from European markets or other unobserved province characteristics on local non-employment rates. While it is not immediately obvious why this shouldn't be the case, we caution that we can't completely rule out the possibility that our estimates are at least in part spurious. However, note that the main goal of the Table is a comparison of the coefficients for Italy and Germany. Even if our estimates contained some bias, there is no obvious reason to expect that it should be more pronounced for Italy than for Germany.

A separate concern is the informal sector in Italy. It is in principle possible that the 
presence of an informal sector in Italy could explain some of the differences with Germany documented in Figure 6 and in columns 1 and 2 of Table 5. If employers in less productive provinces in Italy are forced to pay wages above the equilibrium wage by binding national contracts, they may react by paying workers under the table. If informal jobs are not included in employment measures, our estimates would be biased. Specifically, failure to include informal employment in Italy would lead us to estimate an elasticity of non-employment with respect to value added that is more negative than the true elasticity. We don't expect this bias to be very large in our setting because the employment data that we use should in principle include workers both in the formal and informal sector. As mentioned in Section IV, our data are based on an anonymous survey of individuals not tax data or social security data - and there is no a priori reason to think that workers in our sample have an incentive to misreport their employment status.

Nevertheless, we probe the robustness of our findings in columns 3 and 4 of Table 5 using an alternative measure of employment. This measure is based on estimates of the share of informal employment among all full-time equivalent units of work published by the Italian National Statistical Institute ISTAT taken from its Regional Accounts (Istat, 2014). Notice that adding informal sector employment to Labor Force Survey (LFS) employment implies that employment rates are overestimated as there is a substantial overlap between informal employment and LFS employment. Appendix Figure A-1 shows the fraction of employment in the informal sector, as estimated by ISTAT. We use this measure to inflate the employment rate in each province proportionally to the estimated informal sector. ${ }^{43}$

We find that models based on non-employment rates inflated by ISTAT regional estimates of informal sector yield elasticities not very different from the baseline models. ${ }^{44}$ A comparison of Figure 7 with Figure 6 shows that after correcting for informality, there still is a strong negative correlation of non-employment rates with value added. Table 5 shows that the coefficients based on corrected non-employment rates (columns 3 and 4) are slightly smaller than those in columns 1 and 2, but remain much larger than the corresponding coefficients for Germany. ${ }^{45}$

The effect of nominal wage rigidity on the size of the local informal sector is interesting

\footnotetext{
${ }^{43}$ In particular, we inflate the official employment rate by a factor $\frac{1}{1-e_{\text {inf }}}$ where $e_{\text {inf }}$ is the estimated share of employment in the informal sector.

${ }^{44}$ A proxy for informal sector can be obtained by focusing on the subsample of the Labor Force Survey regarding migrant workers, who are often paid under the table. (?) reports that interregional wage differentials are almost twice as large among migrants than among the native population, while the opposite happens when non-employment rates are considered. In our analysis we cover all employees, including migrant workers.

${ }^{45}$ For completeness, Appendix Figure A-2 replicates Figure 5 using corrected non-employment rates.
} 
in itself. A larger informal sector implies less taxes and social security contributions being collected. In Table 6 we show results of a model where we regress the share of informal employment in a province on mean value added. We find a clear negative correlation, suggesting that informal sector is smaller in provinces where value added is higher. In column 1 we find a coefficient of -2.48 . When we include region fixed effects, the coefficient drops to -0.96 but remains economically and statistically significant.

Overall, we draw three conclusions. First, and most importantly, in Italy non-employment rates are much higher in low productivity provinces than in high productivity provinces. While in Germany there is also a difference between high and low productivity provinces, the difference is significantly smaller in Germany than in Italy, presumably because employers in Germany have more flexibility in setting wages. Second, estimates are robust to including employment in the informal sector. Third, the informal sector in Italy is larger in provinces with low productivity. The higher non-employment rates and higher share of informal sector in low productivity provinces are potentially important unintended consequences of collective bargaining in Italy.

\section{V.D Cost of Living and Real Wages}

Appendix Figures A-3 and A-4 show the spatial distribution of housing prices and overall cost of living (local CPI) in the two countries. Housing prices and cost of living are higher in Northern Italy and West Germany, with the geographic differences slightly more pronounced in Italy. Housing prices and overall cost of living are very highly correlated in both countries.

Figure 8 shows real wages, defined as nominal wages deflated by the index of local cost of living, Local CPI. Real wages in a province measure worker purchasing power. For a given nominal wage, real wages are higher the lower the local cost of living index.

For Italy, the comparison between nominal wages in Figure 3 and real wages in Figure 8 is striking. It indicates that real wages in many provinces of the South are significantly higher than the country mean, despite having low productivity. In Germany the same inversion does not occur. This is consistent with the predictions of our model.

Table 7 quantifies the North-South and West-East differences in nominal and real wages. Columns 1 and 3 show the nominal wage difference between North-South (column 1) and West-East (column 3). Despite the fact that productivity differences are similar in the two countries, conditional on worker characteristics the wage difference between the North and the South in Italy is only $4.2 \%$, while the West-East difference in Germany is seven times larger at $28.2 \%$. This disparity between the two countries is plausibly due to the fact that wages cannot fully adjust in Italy. Columns 2 and 4 show the corresponding 
real wage difference, which becomes negative in Italy. Thus, Southern Italian provinces are characterized by lower nominal wages than Northern provinces but higher real wages as a result of relatively low housing prices and cost of living. In Germany, instead, real wages are higher in more productive provinces. ${ }^{46}$

Figure 9 presents the province-level relationship between log real wages and log value added. Consistent with our model, in Italy, there is a negative relationship, indicating that the most productive provinces tend to have the lowest real wage. In Germany, the relationship is positive.

\section{Aggregate Costs of Spatial Misallocation}

In this Section we estimate the aggregate costs stemming from spatial misallocation in Italy. Misallocation arises because under the current wage setting system, firms in provinces where productivity is low are forced to pay wages above the local market-clearing level. As a consequence, output and employment in those provinces, many of which are in the South, are below what they could be if wages were flexible.

In this respect, the findings in the previous Section are striking. Workers in the South were found to enjoy higher real wages than workers in the North, because nominal wages are similar, but cost of living is lower in the South. However, non-employment is much higher in the South. One way to think about the spatial equilibrium in Italy is that Southern jobs are essentially rationed, with residents queuing to get one. If they succeed, their real wage is higher than in the North. But the higher non-employment means that many residents remain idle in the meantime. This implies an inefficient spatial allocation of resources and possibly large economic costs in terms of forgone earnings and forgone employment. In Germany the spatial equilibrium is different. Because nominal wages are more flexible, there are smaller differences in non-employment rates across regions.

If Italy adopted a collective bargaining system in which nominal wages were allowed to reflect local productivity, output and employment in low-productivity provinces would likely increase, resulting in an overall increase in national aggregate output and aggregate employment. This could happen if, for example, union contracts were negotiated at the provincial level (or plant-level) instead of the national level or if national contracts could

\footnotetext{
${ }^{46}$ One difference between the two countries in terms of data is that the wages we use for Italy are net of taxes. Given a progressive tax scheme, taxes could compress wages and thus exaggerate the patterns we are pointing to in this paper. To adjust for this we use the mean wage of all full time workers in social security records (INPS) gross and net of taxes (from 2015) to generate a net/gross ratio for every province. We then construct the net/gross corrected wages dividing the net ISTAT wage of every province by the net/gross ratio for every province. The results based on corrected wages are in the Appendix Table A-3. The correction does not change our findings.
} 
be indexed to local productivity levels rather than imposing a uniform wage schedule across the board.

Aggregate labor income might increase as well. Our model indicates that total labor income would increase if the elasticity of labor demand is larger than one. Intuitively, in low-productivity provinces wages would decrease relative to the current status quo. But an elastic labor demand implies that the increase in local employment would be proportionally larger than the decline in wages, insuring a positive effect on aggregate labor income. Labor demand is likely to be elastic in the case of a small open economy like a province. $^{47}$

If nominal wages were allowed to reflect local productivity, there would also be some distributional consequences, in the sense that there would be winners and losers relative to the status quo. The main losers would be currently-employed workers in the South, as they would earn lower wages.

To quantify the magnitude of these effects, we provide estimates from two counterfactual exercises. The two exercises are similar in that they both relax wage rigidity in Italy by allowing local wages and local employment to depend on local productivity. They differ in how tight the link with local productivity is allowed to be.

In the first counterfactual scenario (partial adjustment), we seek to estimate what would happen to wages and employment if Italy adopted a version of collective bargaining as flexible as the one that exists in Germany. In practice, we apply to Italy the German elasticity of wages with respect to value added and the elasticity of employment with respect to value added. We set the counterfactual wages and the counterfactual employment in each Italian province based on the province observed value added and the elasticity of wages with respect to value added and employment with respect to value added that we estimated for Germany.

In the second counterfactual scenario (full adjustment), we set counterfactual wages and employment in each province assuming that wages fully adjust to local value added and the employment rate reaches Northern levels, as it would be the case in the standard market-clearing case with no frictions (see the first order conditions in Equation 2).

In both scenarios, we compute counterfactual wages and employment for Italy's South and assume that the North is in full employment. As discussed in Section II, the current

\footnotetext{
${ }^{47}$ There are indications that the aggregate (and the Southern) labor demand in Italy is elastic. In 2015 social security contributions of firms for new hires with permanent contracts were almost fully covered by general tax revenues for three years. Considering the average duration of these contracts, this amounts to a reduction in labor costs of about one-fourth over the lifetime of a new permanent contract job. Hiring in these contracts almost doubled in 2015. Two years later this measure was reintroduced limited to firms operating in the South, and once more generated a strong boost in hiring in those regions.
} 
Italian nationwide contracts can be thought of as setting wages approximately equal to the market-clearing level in the North.

We caution that while the empirical results in the previous section were estimated exclusively from data, the quantification of aggregate losses naturally relies on some assumptions. The estimated effects should therefore be considered as an attempt to assess an order of magnitude, rather than exact figures.

\section{VI.A Assumptions}

Counterfactual 1: partial adjustment. To compute counterfactual mean nominal wage in a province in the South, we take value added in the province as given and we predict local mean wage using the elasticity of wages with respect to value added that we have estimated for Germany. In particular, we use the elasticity reported in column 3 of Table 4 , which is equal to 0.74 . To be clear: we do not assume that the average wages or employment or productivity in Italy are the same as in Germany. Instead, we assume that if in Germany a $10 \%$ productivity difference is associated with a $7.4 \%$ wage difference, the same is true in Italy.

Thus, counterfactual wage in a province $c$ in the South with value added $A_{c}$ is defined as $\left[1-0.74 * \frac{\left(A_{n}-A_{c}\right)}{A_{n}}\right] * W_{n}$ where $A_{n}$ and $W_{n}$ are value added and wage of the median province in the North. Counterfactual wages and employment in the North are set equal to those observed in the data. Consider, for example, a Southern province with value added $10 \%$ below the median province in the North. The counterfactual wage in this province is set $7.4 \%$ lower than the wage that we observe in the data in the median province in the North.

We compute counterfactual employment in a similar way. We assume that the relationship between non-employment and value added in the south is the same as the relationship between non-employment and value added that we estimated for Germany. We use the coefficient in column 5 of Table 5 , which is equal to 0.25 . Counterfactual employment rate in a province $c$ in the South is defined as $\left[1-0.25 * \frac{\left(A_{n}-A_{c}\right)}{A_{n}}\right] * E_{n}$ where $E_{n}$ is employment rate in the median province in the North. For example, counterfactual employment in a province in the South with productivity $10 \%$ below the median province in the North is $2.5 \%$ lower than observed employment in the median province in the North.

In the data, the employment rate (corrected for informal employment) in the median province in the North is $71.23 \%$ and the median wage is 8.7 euros per hour. To probe the robustness of our findings, we also estimate variants of these counterfactuals where the benchmark province is not the median province in the North but it is the median province among the top 5, 10 or 20 provinces in the North in terms of value added. 
Note that the validity of these counterfactual estimates depends on the assumption that estimates for Germany of the elasticity of wages with respect to value added in Table 4 and of the elasticity of non-employment with respect to value added in Table 5 are unbiased. If estimates of these two elasticities are biased by omitted variables, then counterfactual estimates would not be valid. This issue does not arise with the next counterfactual exercise.

Counterfactual 2: full adjustment. In the second counterfactual scenario, we assume that wages in each province fully adjust to local productivity. That is, we assume that if one province is $10 \%$ more productive than another, then its wages are $10 \%$ higher. This is indeed the case in the standard market-clearing case, as evident in the first order conditions in Equation (2).

The counterfactual wage in a province $c$ of the South is defined as $\left[1-\frac{\left(A_{n}-A_{c}\right)}{A_{n}}\right] *$ $W_{n}$ and the counterfactual labor market clears at $E_{c}=E_{n}$. Counterfactual wages and employment in the North are set equal to those observed in the data, as described above.

\section{VI.B Results}

Figure 10 shows how nominal wages and employment would change in Counterfactual 1 (partial adjustment). In particular, it shows the percent difference in wages and employment in each province relative to the status quo. Wages in most Southern provinces would decline, while their employment rate would increase. By assumption, there are no changes in the North. Figures 11 shows how nominal wages and employment would change in Counterfactual 2 (full adjustment). The changes in the two counterfactual scenarios appear very correlated.

Table 8 quantifies the wage and employment changes. Column 1 and 2 report observed and counterfactual wages, employment and aggregate labor income in the South. Columns 3 and 4 are for the North, which does not change by assumption; and columns 5 to 7 are for the nation.

The entry in column 1, first row, for example, indicates that the 2010 mean hourly wage in the South is 8.6 euros in our data. The entry in the second row shows that the mean wage in Southern provinces in Counterfactual 1 would be 7.8, a decrease of on average $5.9 \%$ compared to status quo. Column 5 indicates that the average wage decrease across Italian provinces would be $2.6 \%$.

The fourth row indicates that the status quo average Southern employment rate is $57.3 \%$, after adjusting for informal employment. The fifth row shows that in Counterfactual 1, the employment rate in the Southern provinces would increase by 12.85 percentage points on average. The employment rate across Italian provinces would increase by 5.7 
percentage points, an $11.0 \%$ increase. We see this as an economically large effect.

Since the average wage declines but employment increases, it is unclear what happens to labor income. The bottom panel reports aggregate labor income, scaled in Euros per month per resident. Aggregate labor income is the product of monthly earnings times the employment rate. Monthly earnings are defined as the hourly wage multiplied by 160 , under the assumption that workers work 160 hours a month. It is 766 euros in the status quo in the South. In Counterfactual 1 it increases by 114 euros per month $(16.6 \%$ on average) in the South and $7.45 \%$ across the country.

The changes under Counterfactual 2 are somewhat larger than the changes under Counterfactual 1 , as one might expect, but quantitatively not very different. Incidentally, this suggests that if there is a bias in our estimates of the elasticities in Tables 4 and 5, it should not be too large. Letting nominal wages in each province fully adjust to local productivity would reduce hourly wage by 80 cents and increase employment by 13.9 percentage points in the South, raising income for the average Southern worker, whether employed or not, by about 95 euros a month. For the country as a whole this increase would amount to a 6.25 percentage points increase in employment, corresponding to about 2.5 million additional jobs in the Southern provinces, and to an average increase of about 500 euros of yearly income per working-age person in Italy.

Appendix Tables A-4, A-5 and A-6 repeat the counterfactual calculations for the case in which we use the median of the top 5, 10 and 20 provinces in the North as our status quo productivity baseline. Results are not very sensitive. ${ }^{48}$

With all their obvious limits due to the coarse assumptions on which they are based, these counterfactual exercises highlight the existence of potentially large gains in term of equity and efficiency deriving from a liberalization of wage bargaining across different localities. The costs originating from spatial misallocation in Italy appear to be substantial.

\section{Conclusions}

Centralized wage bargaining systems are common in Europe and have traditionally received substantial attention in the economic literature. But their combined effects on the cost of living, on the geography of employment and wages and their aggregate costs

\footnotetext{
${ }^{48}$ For example, in Appendix Table A-4 average hourly wages in Southern provinces would decrease by 0.98 to 1.45 euros, depending on the scenario, while Southern employment would increase by on average $12.85-14.63$ percentage points. Aggregate earnings in the South would increase by 28 to 61 euros a month, and nationwide aggregate employment would increase by on average $6.21-7.34$ percentage points and aggregate earnings would increase by $0.69 \%-3.35 \%$. As the reference is here the median of some top provinces, we now see variations also in the Northern macro-region.
} 
have not previously been studied. In this paper, we study the local and aggregate effects of national wage bargaining systems by comparing the spatial distribution of wages, nonemployment rates, cost of housing, and real wages in Italy and Germany. The two countries have a similar spatial distribution of firm productivity, but have adopted different models of wage bargaining. Italy sets wages based on nationwide sectoral contracts that allow for minimal local wage adjustments, while Germany has moved toward a more flexible system that allows for local bargaining.

We find that, as a consequence, the spatial distribution of nominal wages is very compressed in Italy, and the relationship between local productivity and local nominal wages is weak or possibly zero. By contrast, Germany has significantly more spatially-dispersed wages and a much tighter link between wages and local productivity.

These wage rigidities generate economically costly inefficiencies in Italy. We find that provinces with low productivity have significantly higher non-employment rates than provinces with high productivity, because employers in low productivity provinces cannot lower wages and end up hiring fewer workers. We also uncover a negative relationship between real wages and local value added in Italy. Despite having higher productivity, the North has lower real wages than the South, since the latter has low housing costs but similar nominal wages. This means that, conditional on having a job, an Italian worker is better off in the South in terms of purchasing power. Unsurprisingly, about 80 per cent of applicants for public jobs in national competitions (concorsi) come from Southern regions, schools in the North suffer a chronic lack of teachers and public administrations find it hard to fill the vacancies in Northern provinces, and there is a strong demand of public sector workers to be allotted to Southern provinces. At the same time, the probability of having a job is higher in the North. Thus, national wage contracts have created a spatial equilibrium where workers queue for jobs in the South and remain unemployed while waiting. By contrast, in Germany real wages in the West are not significantly lower than in the East, since nominal wages are spatially more flexible.

From a macro-economic point of view, we find that the Italian wage bargaining system generates significant economic costs in terms of forgone aggregate earnings and employment. If nominal wages were allowed to reflect local productivity, aggregate employment and aggregate earnings would significantly increase in Italy. Based on reasonable assumptions, we estimate that aggregate Southern employment would increase by 12.85 - 13.92 percentage points. Aggregate earnings in the South would increase by $94-114$ euros a month. Nationwide, we estimate that aggregate employment would increase by 5.77 to 6.25 percentage points or about 2.5 million jobs, and aggregate earnings would increase by $6.22 \%$ to $7.45 \%$. In per capita terms, this amounts to around $500-600$ euros 
per capita per year across all working-age adults, not just the employed. This could happen if Italy adopted a system similar to Germany's, where union contracts can be fully negotiated at the firm or provincial level instead of the national level. 


\section{References}

Adda, J. (2018): Regional Wage Disparities and Migration.

Ahlfeldt, G. M., S. J. Redding, D. M. Sturm, and N. Wolf (2015): The economics of density: Evidence from the Berlin Wall. Econometrica, vol. 83, pp. 2127-2189.

Andersen, T. M. et al. (2003): Wage formation and European integration. Tech. rep., Directorate General Economic and Financial Affairs (DG ECFIN), European Commission.

Atkinson, T. and A. Brandolini (2006): The panel of Country Approach to Explain Income Inequality: An Interdisciplinary Research Agenda. In: Mobility and Inequality. Frontiers of Research in Sociology and Economics. Princeton University Press, pp. 400-488.

Banfield, E. C. (1958): The Moral Basis of a Backward Society. New York : The Free Press.

Belloc, M., P. Naticchioni, and C. Vittori (2018): Urban Wage Premia, Cost of Living, and Collective Bargaining. CESifo Group Munich.

Bigoni, M., S. Bortolotti, M. Casari, D. Gambetta, and F. Pancotto (2016): Amoral Familism, Social Capital, or Trust? The Behavioural Foundations of the Italian North-South Divide. Economic Journal, vol. 126, pp. 1318-1341.

Boeri, T., A. Brugiavini, and L. Calmfors (2001): The role of unions in the twenty-first century: a report for the Fondazione Rodolfo Debenedetti. OUP Oxford.

Brändle, T., W. D. Heinbach, and M. F. Maier (2011): Tarifliche Öffnung in Deutschland: Ausmaß, Determinanten, Auswirkungen. Zeitschrift für Arbeitsmarktforschung, vol. 44, pp. 163-172.

Brandolini, A., P. Casadio, P. Cipollone, M. Magnani, A. Rosolia, and R. Torrini (2007): Employment growth in Italy in the 1990s: institutional arrangements and market forces. In: Social pacts, employment and growth. Springer, pp. 31-68.

Brunello, G., C. Lupi, and P. Ordine (2000): Regional Disparities and the Italian NAIRU. Oxford Economic Papers, vol. 52, pp. 146-177.

- (2001): Widening differences in Italian regional unemploymen. Labour Economics, vol. 8, pp. 103-129.

Buonanno, P., R. Durante, G. Prarolo, and P. Vanin (2015): Poor Institutions, Rich Mines: Resource Curse and the Origins of the Sicilian Mafia. Economic Journal, vol. 125, pp. 175-202.

Burda, M. and J. Hunt (2001): From Reunification to Economic Integration: Productivity and the Labor Market in Eastern Germany. Brookings Papers on Economic Activity, pp. $1-71$.

Calmfors, L. and H. Horn (1986): Employment policies and centralized wage-setting. Economica, pp. 281-302.

Card, D., T. Lemieux, and W. Riddel (2004): Unions and wage inequality. Journal of Labor Research, vol. 25, pp. 519-559. 
Casadio, P. (2003): Wage formation in the Italian private sector after the 1992-93 income policy agreements. MPRA Paper.

- (2008): Ruolo e prospettive della contrattazione aziendale integrativa: informazioni dall'indagine della banca d'Italia. Paper per il Convegno annuale 2008 dell'AIEL.

Checchi, D. and C. Lucifora (2002): Unions and labor market institutions in Europe. vol. 35, pp. 363-408.

CNEL (2018): Annual Report 2016-17 on the Labour Market and Collective Bargaining.

Dauth, W., S. Findeisen, E. Moretti, and J. Suedekum (2018): Matching in Cities. NBER WP 25227.

Du Caju, P., E. Gautier, D. Momferatou, and M. E. Ward-Warmedinger (2008): Institutional features of wage bargaining in 23 European countries, the US and Japan. ECB Working Paper Series.

Duranton, G. and D. Puga (2014): The growth of cities. In: Handbook of economic growth, vol. 2. Elsevier, pp. 781-853.

Dustmann, C., B. Fitzenberger, U. Schönberg, and A. Spitz-Oener (2014): From sick man of Europe to economic superstar: Germany's resurgent economy. Journal of Economic Perspectives, vol. 28, pp. 167-88.

Dustmann, C., J. Ludsteck, and U. Schönberg (2009): Revisiting the German wage structure. The Quarterly Journal of Economics, vol. 124, pp. 843-881.

Erickson, C. L. and A. Ichino (1994): Lump-Sum Bonuses in Union Contracts. Advances in Industrial and Labor Relations, vol. 6, pp. 183-218.

Fajgelbaum, P. D., E. Morales, J. C. S. Serrato, and O. M. Zidar (2015): State taxes and spatial misallocation. Tech. rep., National Bureau of Economic Research.

Flanagan, R. (1999): Macroeconomic Performance and Collective Bargaining: An International Perspective. Journal of Economic Literature, vol. 37, pp. 1150-1175.

Garnero, A. (2018): The dog that barks doesn't bite: coverage and compliance of sectoral minimum wages in Italy. IZA Journal of Labor Policy, vol. 7, p. 3.

Guiso, L., P. Sapienza, and L. Zingales (2004): The role of social capital in financial development. American Economic Review, vol. 94, pp. 526-556.

Hijzen, A. and P. Martins (2016): No Extension without Representation? Evidence from a Natural Experiment in Collective Bargaining. IMF Working Paper, vol. 16.

Hornbeck, R. and E. Moretti (2018): Who Benefits From Productivity Growth? Direct and Indirect Effects of Local TFP Growth on Wages, Rents, and Inequality. Tech. rep., National Bureau of Economic Research.

Hsieh, C.-T. and E. Moretti (forthcoming): Housing constraints and spatial misallocation. American Economic Journal: Macroeconomics. 
Ichino, A. and G. Maggi (2000): Work Environment and Individual Background: Explaining Regional Shirking Differentials in a Large Italian Firm. Quarterly Journal of Economics, vol. 115, pp. 1057-1090.

IStat (2000): La flessibilità del mercato del lavoro nel periodo 1995-96. Collana Informazioni.

Istat (2014): Noi Italia. 100 statistiche per capire il Paese in cui viviamo.

Jappelli, T. and L. Pistaferri (2000): The dynamics of household wealth accumulation in Italy. Fiscal Studies, vol. 21, pp. 269-295.

- (2010): Does consumption inequality track income inequality in Italy? Review of Economic Dynamics, vol. 13, pp. 133-153.

Kline, P. and E. Moretti (2013): Place based policies with unemployment. American Economic Review, Papers and Proceedings, vol. 103, pp. 238-43.

Kohaut, S. and C. Schnabel (2007): Tarifliche Öffnungsklauseln-Verbreitung, Inanspruchnahme und Bedeutung. Sozialer Fortschritt, pp. 33-40.

Manacorda, M. (2004): Can the Scala Mobile explain the fall and rise of earnings inequality in Italy? A semiparametric analysis, 1977-1993. Journal of Labor economics, vol. 22, pp. 585-613.

Manacorda, M. and B. Petrongolo (2001): Regional mismatch and unemployment: theory and evidence from Italy, 1977-1998. Journal of Population Economics, vol. 19, pp. 137-162.

Moretti, E. (2011): Local labor markets. In: Handbook of labor economics, vol. 4. Elsevier, pp. 1237-1313.

— (2013): Real wage inequality. American Economic Journal: Applied Economics, vol. 5, pp. 65-103.

OECD (2017): Collective bargaining in a changing world of work. OECD Employment Outlook 2017.

- (2018a): Regional Statistics. Date retrieved from https://stats.oecd.org on $17 / 10 / 2018$.

- (2018b): The role of collective bargaining systems for good labour market performance. OECD Employment Outlook 2018.

Putnam, R., R. Leonardi, and R. Nanetti (1993): Making Democracy Work: Civic Traditions in Modern Italy. Princeton University Press.

Redding, S. J. (2013): Economic geography: a review of the theoretical and empirical literature. In: Palgrave handbook of international trade. Springer, pp. 497-531.

Restuccia, D. and R. Rogerson (2017): The causes and costs of misallocation. Journal of Economic Perspectives, vol. 31, pp. 151-74.

Saggio, R., D. Daruich, and S. di Addario (2018): The Effects of Partial Employment Protection Reforms: Evidence from Italy. 
Schnabel, C. (1998): The reform of collective bargaining in Germany: corporatist stability vs. firm flexibility. The German Model of Industrial Relations between Adaptation and Erosion, pp. 83-95.

Traxler, F., S. Blaschke, B. Kittel et al. (2001): National labour relations in internationalized markets: A comparative study of institutions, change, and performance. Oxford University Press Oxford.

Van Ruysseveldt, J. and J. Visser (1996): Industrial relations in Europe. Traditions and transitions. 
Table 1: Example of a collective bargaining contract in Italy: Construction sector, 2016

\begin{tabular}{lcccc}
\hline Cost component & Mean & Min & Max & SD \\
\hline Minimum/Floor & 4.86 & 4.86 & 4.86 & 0.00 \\
Indexation to inflation & 2.96 & 2.96 & 2.96 & 0.00 \\
Cost of living allowance & 0.06 & 0.06 & 0.06 & 0.00 \\
Variable component of pay & 0.15 & 0.04 & 0.50 & 0.09 \\
Sectoral allowance & 1.11 & 0.91 & 1.26 & 0.07 \\
Total : Hourly components of pay & 9.02 & 8.79 & 9.37 & 0.09 \\
\hline Remuneration for national holidays & 0.61 & 0.60 & 0.62 & 0.00 \\
Compensation for yearly vacation & 0.47 & 0.46 & 0.48 & 0.01 \\
Contribution to mutual sectoral fund & 1.77 & 1.73 & 1.80 & 0.01 \\
Transport allowance & 0.29 & 0.05 & 1.40 & 0.20 \\
Compensation for training & 0.18 & 0.18 & 0.18 & 0.00 \\
Contribution to mutual fund for injury & 0.21 & 0.20 & 0.21 & 0.00 \\
Total : Additional costs & 3.46 & 3.19 & 4.64 & 0.21 \\
\hline Contribution to social security & 4.38 & 4.23 & 4.78 & 0.09 \\
Contribution to accident insurance & 1.62 & 1.57 & 1.77 & 0.03 \\
Contribution to special contruction worker fund & 0.78 & 0.39 & 1.16 & 0.15 \\
Total : Social security and accident insurance & 6.78 & 6.34 & 7.57 & 0.23 \\
\hline Allowance for meals & 0.60 & 0.12 & 1.75 & 0.26 \\
Severance & 0.98 & 0.92 & 1.39 & 0.05 \\
Mobility allowance, complemenatary allowances & 3.20 & 3.13 & 3.25 & 0.02 \\
Contribution to pension fund & 0.06 & 0.06 & 0.06 & 0.00 \\
\hline Total average hourly cost of labor & 24.08 & 22.98 & 26.04 & 0.62 \\
\hline & & & & \\
\hline
\end{tabular}

Note: The table shows the various components that are used to set compensation for workers in "Level 1 " of the bargaining agreement for the May 2016 Construction sector ("Contratto Collettivo Nazionale per i Lavoratori Edili"). Monetary figures are in Euros. Entries show the degree of permitted labor cost differentiation across provinces for each specific component of labor costs. 
Table 2: Median monthly wages at three employers

\begin{tabular}{lccc}
\hline & Median North & Median Center & Median South \\
Private sector: Bank teller & 1,666 & 1,667 & 1,664 \\
Private sector: Energy company & 2,736 & 2,923 & 2,931 \\
Public sector: Elementary school teacher & 1,305 & 1,305 & 1,305 \\
\hline
\end{tabular}

Note: In the first row, we show the median monthly wage for a male bank teller with 10-20 years of experience in a large Italian bank, at occupational level 6 ("Inquadramento unico: impiegato"). The data come from years 1993-1995 and sample sizes are 423, 140, and 105 for the North, Center, and South respectively. The second row shows median monthly wages in a large company in the energy sector operating in almost all Italian provinces in 2016. We include men with less than 10 years of experience and with a permanent full-time contract. The sample size is 91, 64 and 130 individuals for the North, Center, and South respectively. In the third row we show the wage of an elementary school teacher with 5 years of seniority in 2014. 
Table 3: Percentage of workers covered by collective bargaining and opening clauses in Germany

\begin{tabular}{ccccc}
\hline Year & \multicolumn{2}{c}{ \% workers under } & \multicolumn{2}{c}{ \% workers subject to } \\
& industry contract & \multicolumn{2}{c}{ opening clauses } \\
\hline & $(1)$ & $(2)$ & $(3)$ & $(4)$ \\
& West & East & West & East \\
\hline 1996 & 69.22 & 56.30 &. &. \\
1998 & 67.77 & 50.46 &. &. \\
2001 & 63.11 & 44.60 &. &. \\
2003 & 62.08 & 42.58 &. &. \\
2005 & 58.74 & 41.89 & 33.36 & 23.69 \\
2007 & 56.18 & 40.57 & 38.30 & 28.19 \\
2009 & 55.46 & 38.35 &. &. \\
2011 & 53.70 & 37.44 & 47.27 & 40.01 \\
2013 & 52.03 & 35.13 &. &. \\
\hline
\end{tabular}

Note: This table shows the coverage of union contracts and opening clauses ("exceptions to union contracts on wage or hours"). The data are obtained from the German Institute for Employment Research (IAB). ${ }^{49}$ The figures in this table show the fraction of workers working for an employer in the West and in the East who states to apply industry contracts or to use opening clauses respectively. 
Table 4: Regression of mean nominal wages on mean value added

\begin{tabular}{lcccc}
\hline & \multicolumn{2}{c}{ Italy } & \multicolumn{2}{c}{ Germany } \\
\hline & $(1)$ & $(2)$ & $(3)$ & $(4)$ \\
\hline Log value added & 0.195 & 0.137 & 0.736 & 0.379 \\
& $(0.013)$ & $(0.019)$ & $(0.013)$ & $(0.008)$ \\
\hline Region FE: & No & Yes & No & Yes \\
Provinces: & 103 & 103 & 96 & 96 \\
\hline
\end{tabular}

Note: Entries are the coefficients of log mean value added in a regression of log mean nominal wage on log value added of each province pooling years 2000-2014 for Germany and 2009-2013 for Italy. All regressions include year fixed effects. Regressions in columns 2 and 4 include fixed effects for the North in Italy and the West in Germany. Standard errors in parentheses. 
Table 5: Regression of non-employment rate on mean value added

\begin{tabular}{lcccccc}
\hline & \multicolumn{3}{c}{ Italy } & \multicolumn{2}{c}{ Germany } \\
& Uncorrected & \multicolumn{2}{c}{ Corrected } & & \\
\hline & $(1)$ & $(2)$ & $(3)$ & $(4)$ & $(5)$ & $(6)$ \\
\hline Log value added & -1.434 & -0.534 & -1.259 & -0.403 & -0.252 & -0.110 \\
& $(0.030)$ & $(0.031)$ & $(0.042)$ & $(0.050)$ & $(0.024)$ & $(0.031)$ \\
\hline Region FE: & No & Yes & No & Yes & No & Yes \\
Provinces: & 103 & 103 & 103 & 103 & 96 & 96 \\
\hline
\end{tabular}

Note: Entries are the coefficients of log mean value added in a regression of the log non-employment rate among 15-64-year-olds on $\log$ mean value added of each province pooling years 2001-2015 for Germany, 2004-2015 for Italy in columns 1 and 2, and 2004-2011 for Italy in columns 3 and 4. Columns 1 and 2 (uncorrected) do not account for irregular employment in Italy, while columns 3 and 4 use estimates from Istat, 2014 to account for irregular employment. All regressions include year fixed effects. Regressions in columns 2, 4 and 6 include fixed effects for the North in Italy and the West in Germany. Standard errors in parentheses. 
Table 6: Regression of the share of informal employment on mean value added

\begin{tabular}{lcc}
\hline & $(1)$ & $(2)$ \\
\hline Log value added & -2.487 & -0.962 \\
& $(0.058)$ & $(0.065)$ \\
\hline Region FE: & No & Yes \\
Provinces: & 103 & 103 \\
\hline
\end{tabular}

Note: Entries are the coefficients of log mean value added in a regression of the log share of total work provided informally on log mean value added for each province pooling years 2001-2011. All regressions include year fixed effects. Regression in column 2 include fixed effects for the North. Standard errors in parentheses. 
Table 7: Average wage differences between macro regions

\begin{tabular}{lcccc}
\hline & \multicolumn{2}{c}{$\begin{array}{c}\text { North - South } \\
\text { in Italy }\end{array}$} & \multicolumn{2}{c}{$\begin{array}{c}\text { West - East } \\
\text { in Germany }\end{array}$} \\
\hline & $(1)$ & $(2)$ & $(3)$ & $(4)$ \\
& Nominal & Real & Nominal & Real \\
\hline \% Difference & 0.0425 & -0.0921 & 0.282 & 0.176 \\
& $(0.003)$ & $(0.017)$ & $(0.003)$ & $(0.007)$ \\
\hline Provinces: & 103 & 103 & 96 & 96 \\
\hline
\end{tabular}

Note: This table reports the coefficients of regressions of log mean conditional wages of all local areas on an indicator of North/West. We pool all available years. For nominal wages: 2000-2014 (Germany) and 2009-2013 (Italy). For real wages: 2004-2014 (Germany) and 2009-2011 (Italy). All specifications control for year fixed effects. Standard errors in parentheses. 
Table 8: Counterfactuals exercises for Italy

\begin{tabular}{|c|c|c|c|c|c|c|c|}
\hline & \multicolumn{2}{|c|}{ South } & \multicolumn{2}{|c|}{ North } & \multicolumn{3}{|c|}{ Italy } \\
\hline & $(1)$ & $(2)$ & (3) & (4) & $(5)$ & (6) & $(7)$ \\
\hline & Level & Change & Level & Change & Level & Change & Change $\%$ \\
\hline \multicolumn{8}{|c|}{ Average hourly wage: in Euros } \\
\hline Status quo & 8.36 & & 8.68 & & 8.54 & & \\
\hline Counterfactual 1 & 7.84 & -0.53 & 8.68 & 0.00 & 8.30 & -0.24 & -2.65 \\
\hline Counterfactual 2 & 7.56 & -0.80 & 8.68 & 0.00 & 8.18 & -0.36 & -4.13 \\
\hline \multicolumn{8}{|c|}{ Employment rate: in \% corrected for informal work } \\
\hline Status quo & 57.32 & & 71.00 & & 64.86 & & \\
\hline Counterfactual 1 & 70.17 & 12.85 & 71.00 & 0.00 & 70.63 & 5.77 & 11.04 \\
\hline Counterfactual 2 & 71.24 & 13.92 & 71.00 & 0.00 & 71.11 & 6.25 & 11.95 \\
\hline \multicolumn{8}{|c|}{ Aggregate labor income per capita: in Euros per month } \\
\hline Status quo & 766.63 & & 986.68 & & 887.89 & & \\
\hline Counterfactual 1 & 881.00 & 114.37 & 986.68 & 0.00 & 939.24 & 51.34 & 7.45 \\
\hline Counterfactual 2 & 861.44 & 94.81 & 986.68 & 0.00 & 930.46 & 42.56 & 6.22 \\
\hline
\end{tabular}

Note: In each panel the first row corresponds to the status quo in 2010. The second row corresponds to the first counterfactual scenario (partial adjustment), while the third row is for the second counterfactual scenario (full adjustment). Entries in columns (1), (3) and (5) are averages of hourly nominal wages, employment rates and aggregate labor income levels per capita across provinces of the South, of the North or of Italy as a whole, respectively. Entries in columns (2), (4) and (6) are the average changes corresponding to each counterfactual scenario. Column (7) shows the average percentage change across all Italian provinces, corresponding to each counterfactual scenario. Aggregate labor income in a province is the product of the average monthly earnings times the employment rate. Monthly earnings are the product of the hourly wage times 160 (which implies assuming 160 working hours per month). 
Figure 1: Labor demand

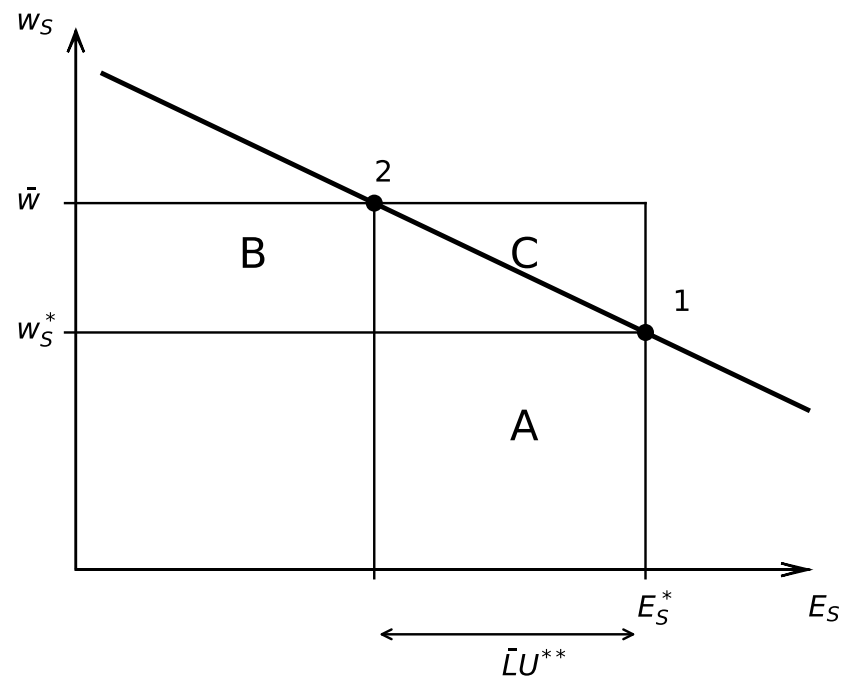

Note: Point 1 and 2 are the free market equilibrium and the fixed wage equilibrium, respectively. Setting the wage above the market wage raises the wage that employed workers receive but lowers employment. Aggregate labor income is larger if the negative effect of employment losses (the area of A) exceeds the positive effect from the higher wage (the area of B). 
Figure 2: Mean value added per worker
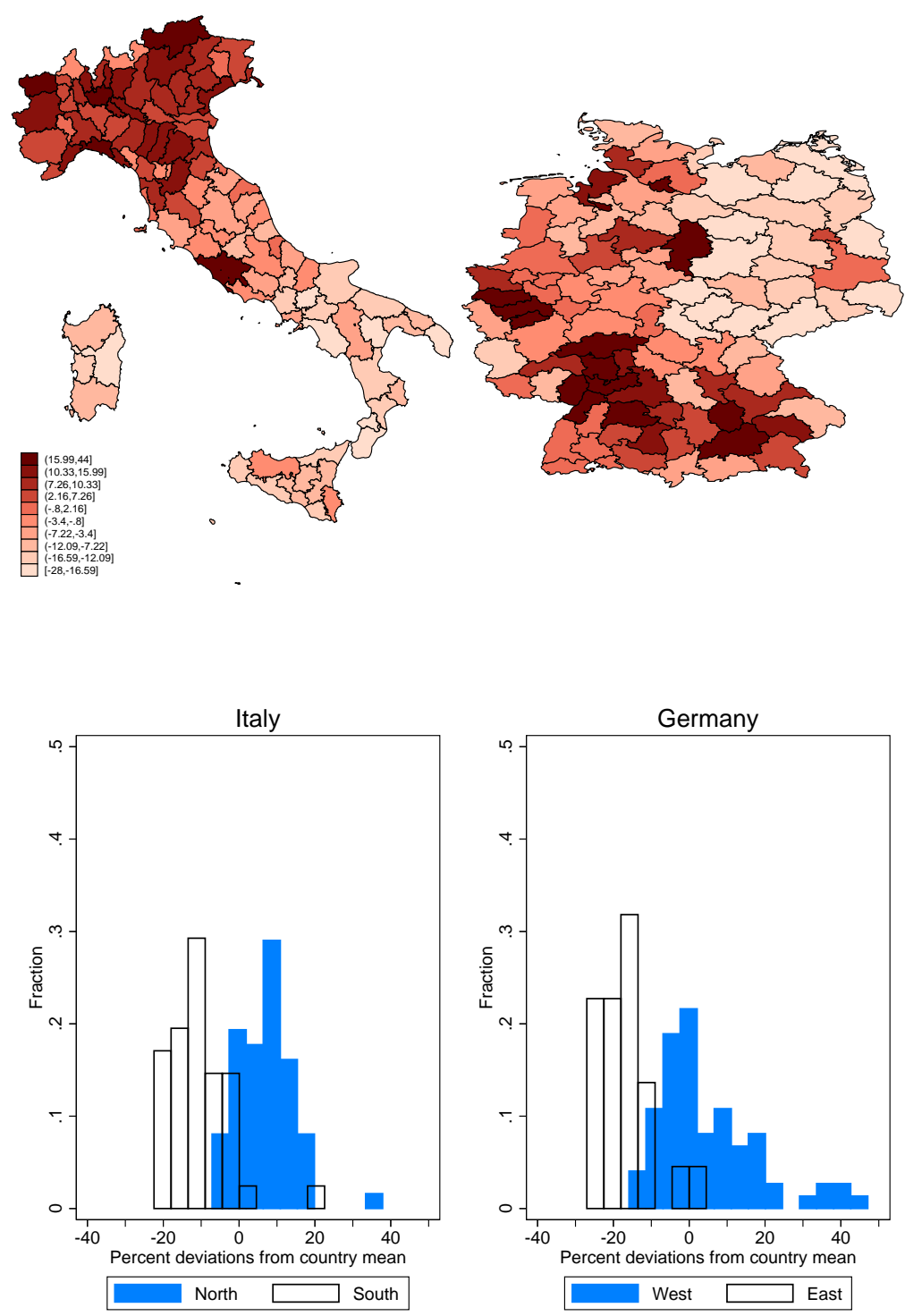

Note: This figure plots deviations from the country mean of the gross value added per worker of each province in 2010. Means across local areas are not weighted by population. 
Figure 3: Nominal wages
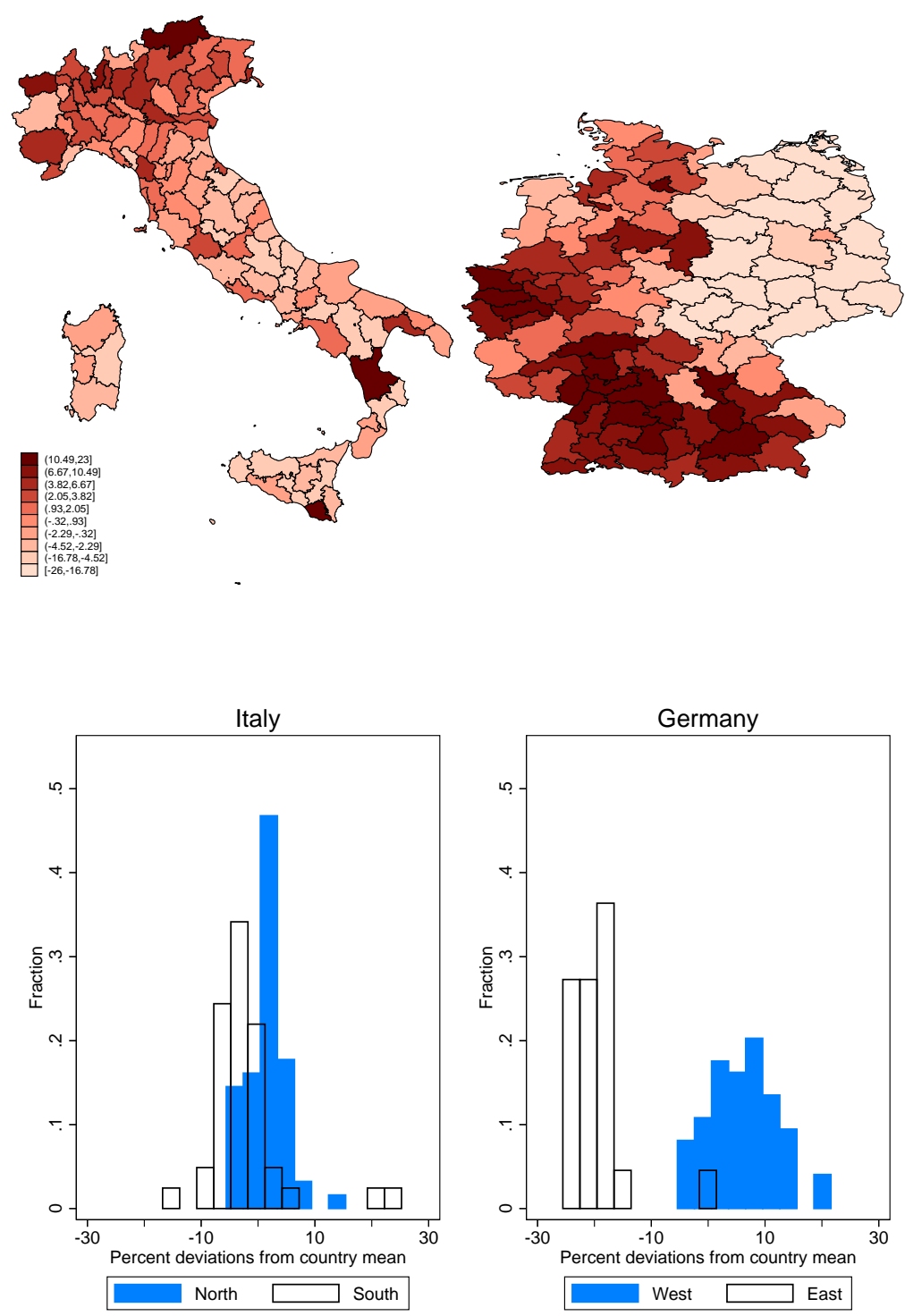

Note: This figure plots deviations from the country mean of the nominal wages in euros (corrected for work force composition) of each province in 2010. Means are not weighted by population. 
Figure 4: Nominal wage and value added

(a) Italy

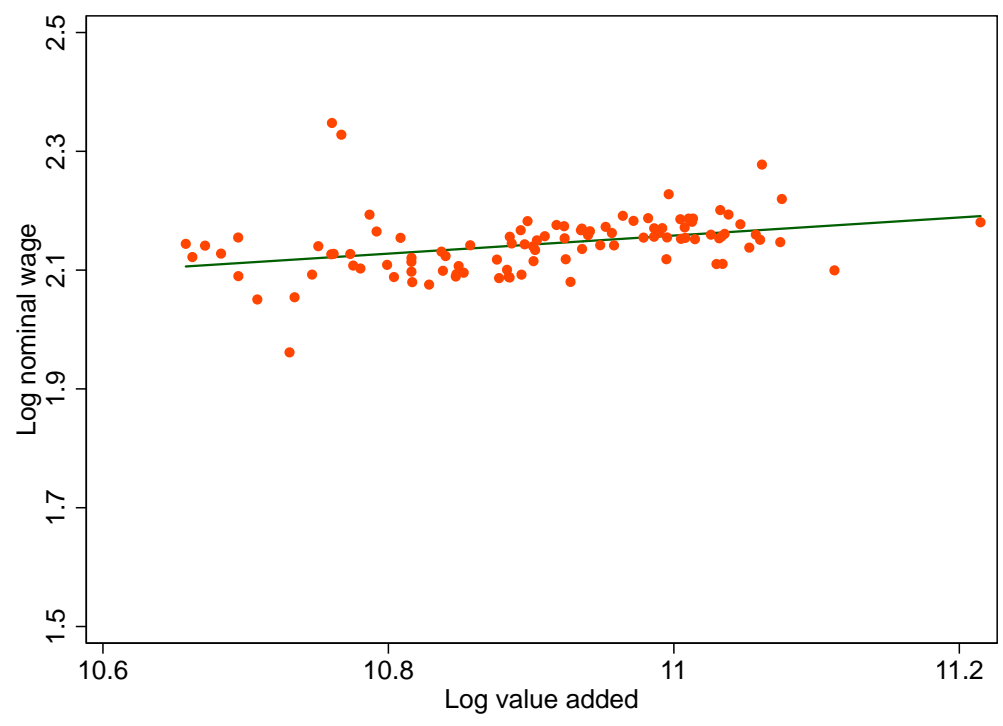

(b) Germany

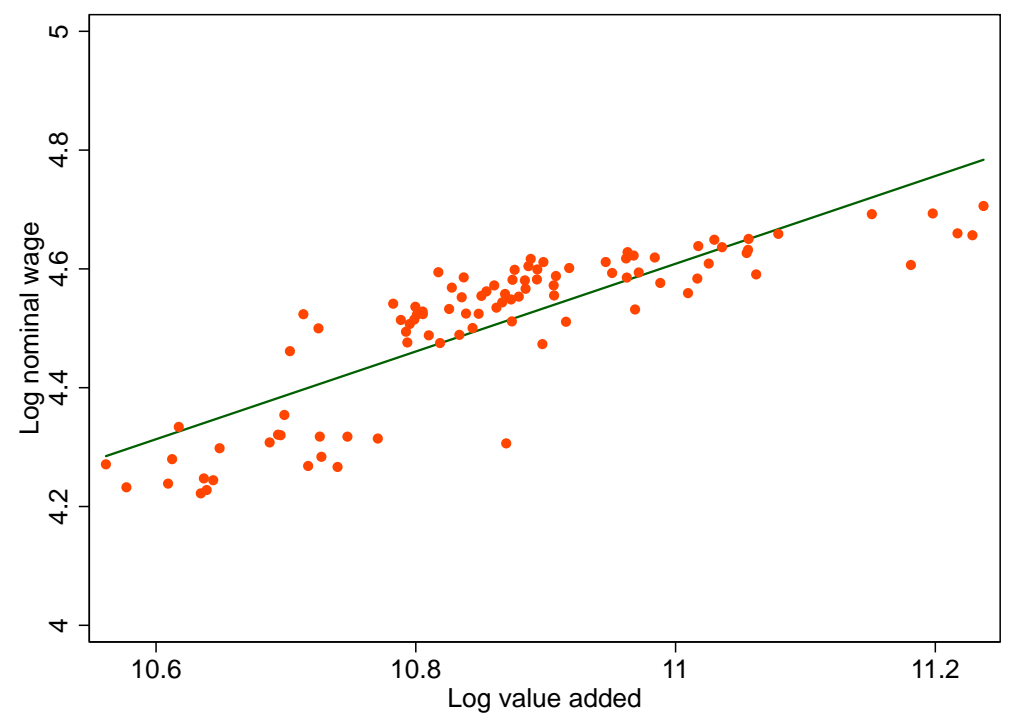

Note: This figure shows the relationship between log mean conditional nominal wages and log value added in 2010, across provinces. Each province is represented by a dot. 
Figure 5: Non-employment rate
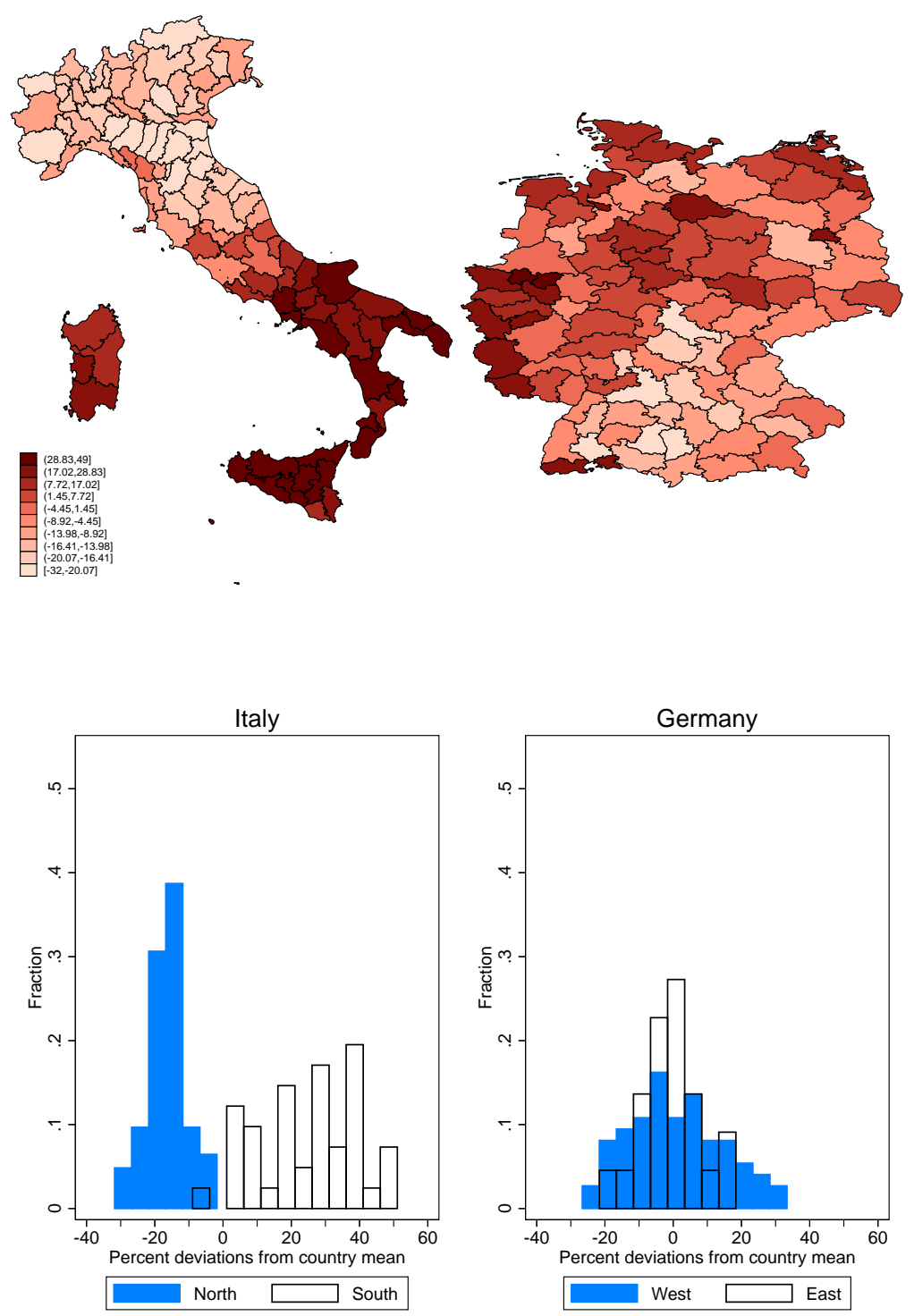

Note: This figure plots deviations from the country mean of the non-employment rate of 15-64-year-olds for each province in 2010. Means are not weighted by population. 


\section{Figure 6: Non-employment and value added}

(a) Italy

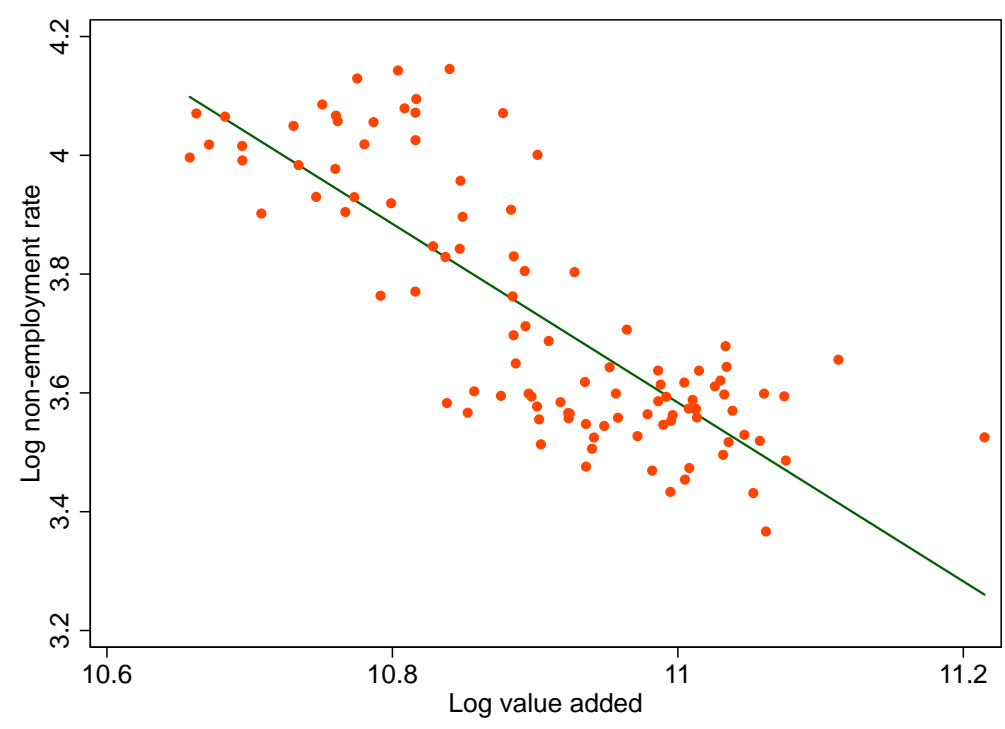

(b) Germany

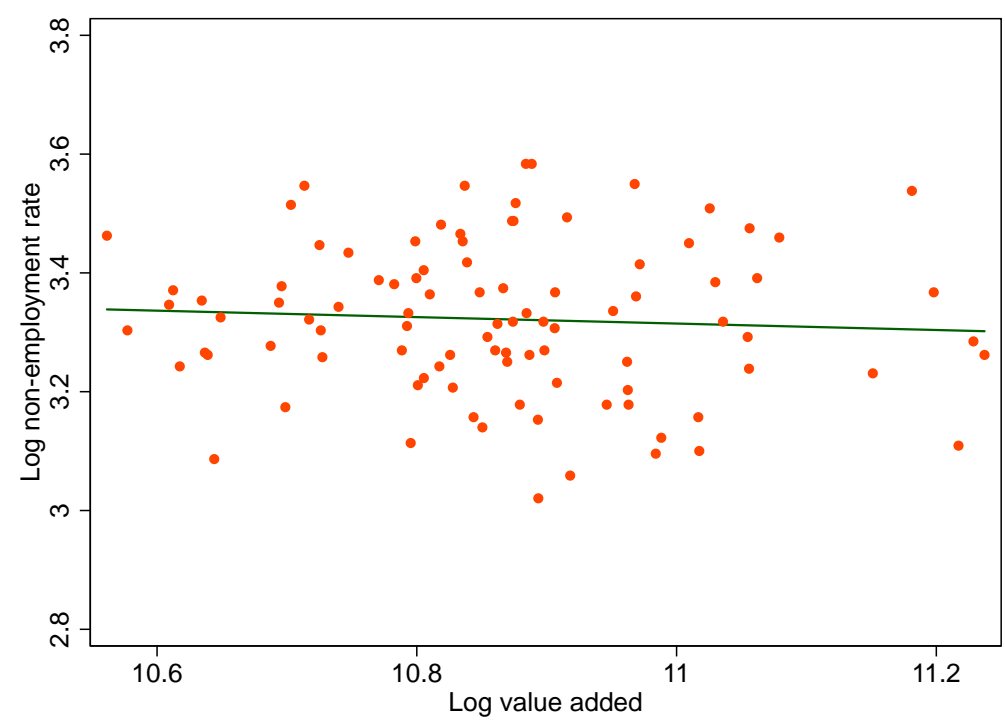

Note: This figure shows the relationship between the log non-employment rate among 15-64-year-olds and $\log$ value added across provinces in 2010. Each province is represented by a dot. 


\section{Figure 7: Non-employment corrected for informal employment and value added}

(a) Italy

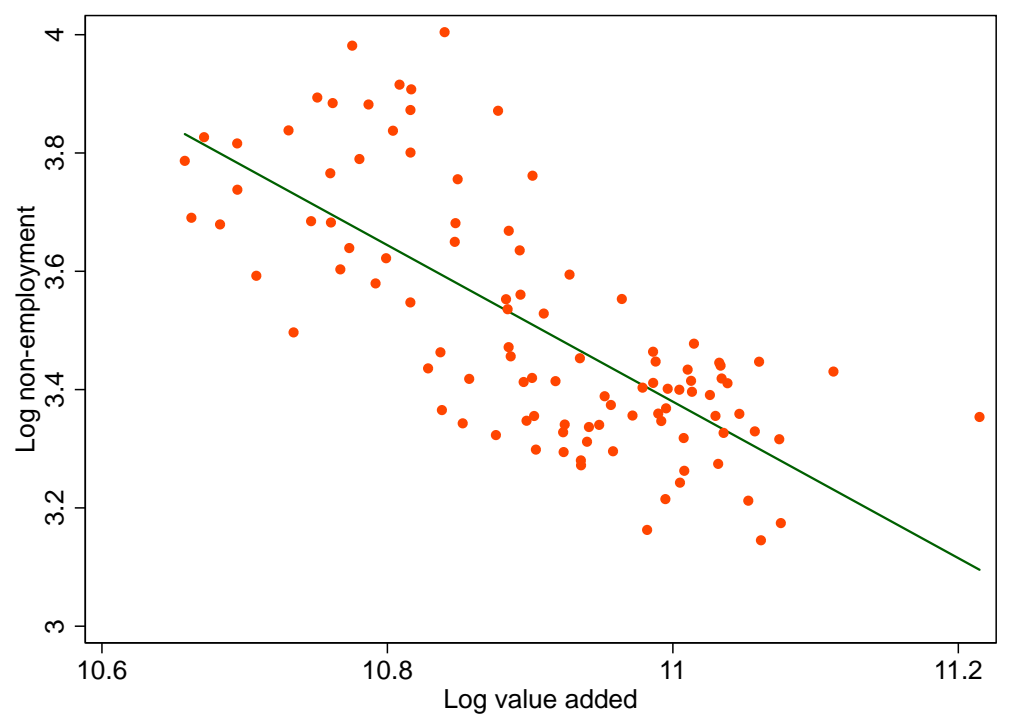

Note: This figure shows the relationship between the log non-employment rate among 15-64-year-olds taking into account informal work, and log value added across provinces in 2010. Each province is represented by a dot. 
Figure 8: Real wages
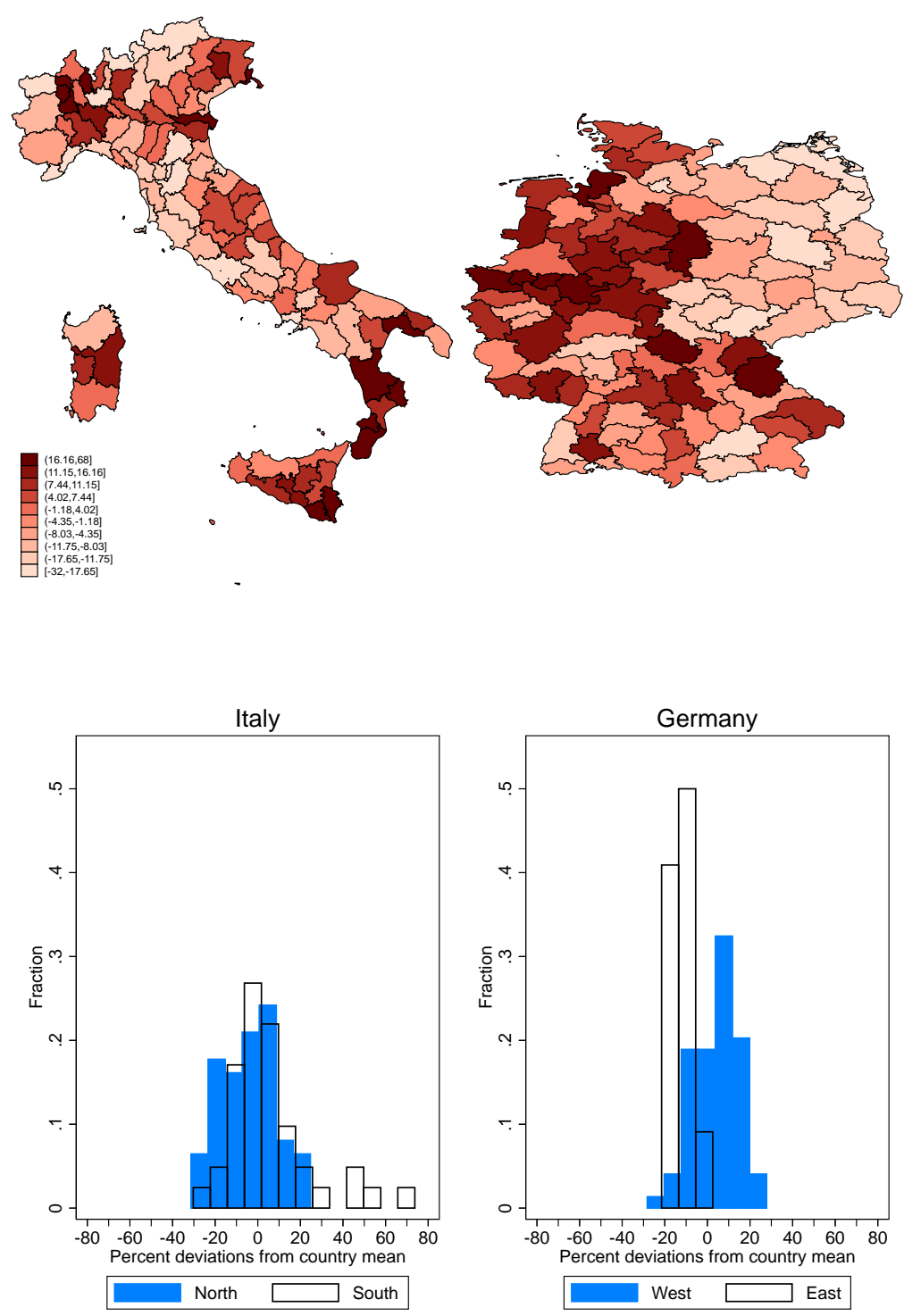

Note: Deviations from the country mean of the mean conditional real wages in euros (conditional nominal wages adjusted for consumer prices, as explained in Section IV) of each province in 2010. Means are not weighted by population. 
Figure 9: Real wage and value added

(a) Italy

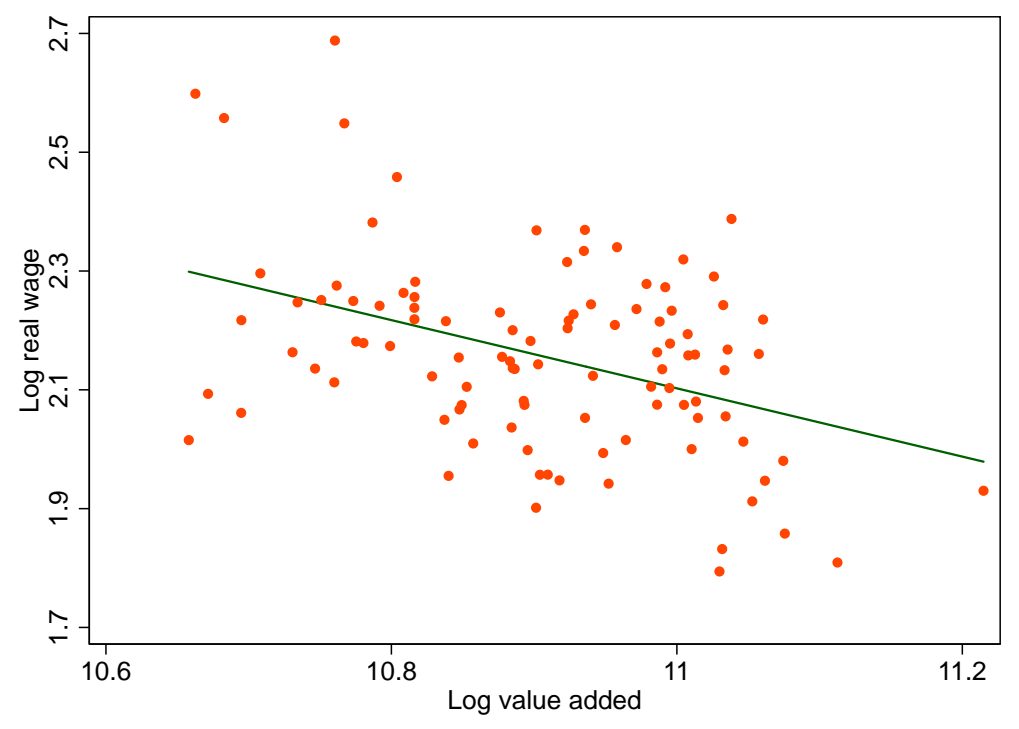

(b) Germany

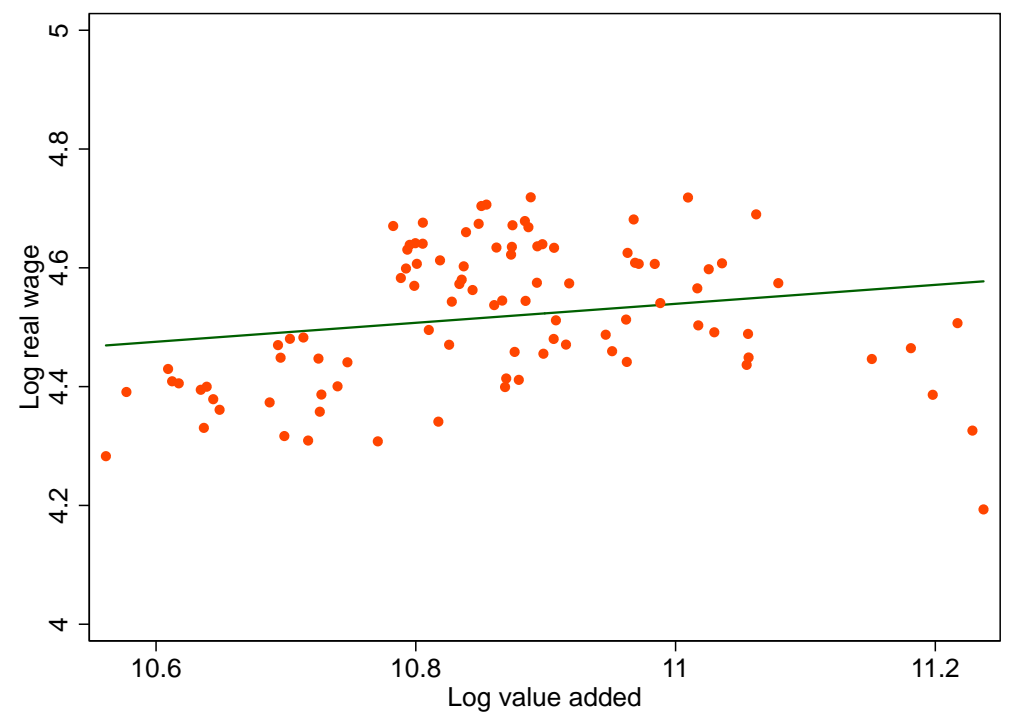

Note: This figure shows the relationship between log mean conditional real wages (log conditional nominal wages adjusted for consumer prices, as explained in Section IV) and log mean value added across provinces in 2010. Each province is represented by a dot. 


\section{Figure 10: Change in wages and employment by province in counterfactual 1}

(a) Nominal wages

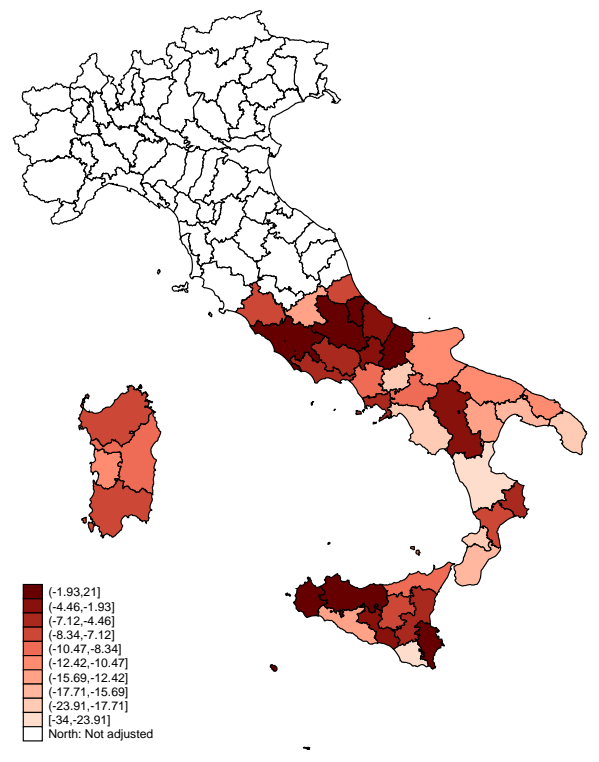

(b) Employment

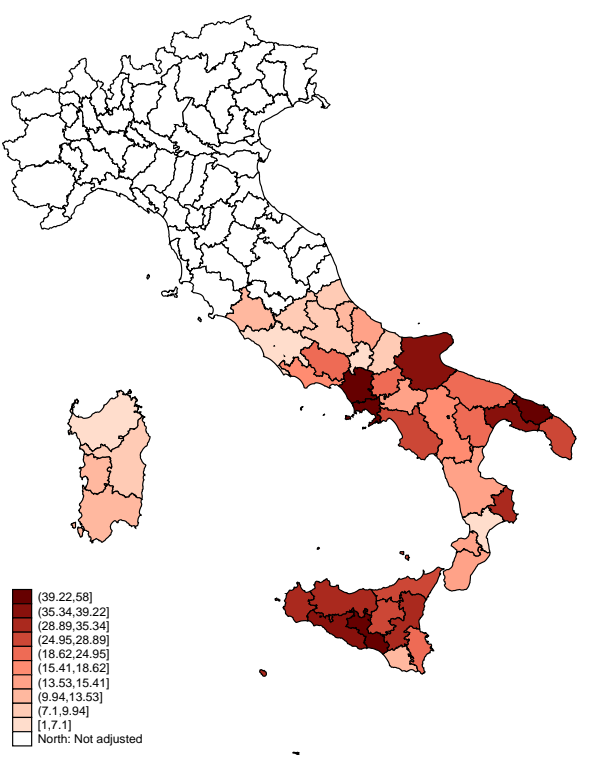

Note: The maps show the percent change in mean wage and employment rate in each province under counterfactual 1. For nominal wages, a lighter color indicates a larger in size negative adjustment. For employment a darker color indicates a larger in size positive adjustment. There is no change in the North by assumption. 


\section{Figure 11: Changes in wages and employment by province in counterfactual 2}

(a) Nominal wages

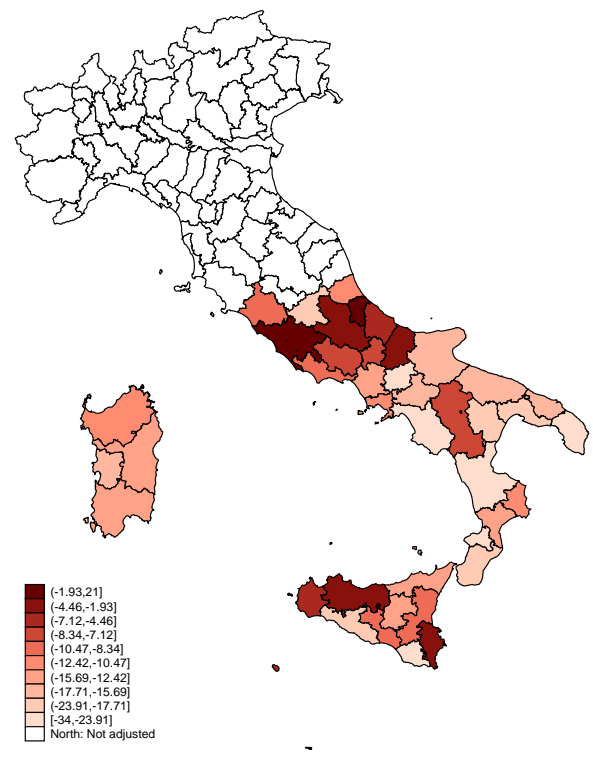

(b) Employment

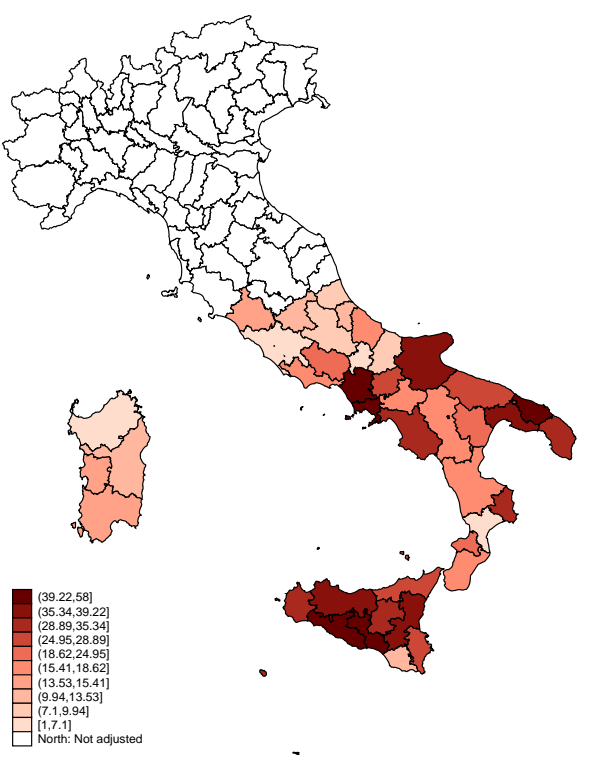

Note: The maps show the percent change in mean wage and employment rate in each province under counterfactual 2. For nominal wages, a lighter color indicates a larger in size negative adjustment. For employment a darker color indicates a larger in size positive adjustment. There is no change in the North by assumption. 


\section{ONLINE APPENDIX}

Table A-1: Summary statistics - 2010

\begin{tabular}{lccc}
\hline Italy & Mean & SD & N \\
\hline Value added per worker & 54837 & 6227 & 103 \\
Local CPI & 100.0 & 16.19 & 103 \\
Local housing price & 100.0 & 25.17 & 103 \\
Nominal wage - hourly & 8.5 & 0.44 & 103 \\
Real wage - hourly & 8.8 & 1.47 & 103 \\
Non-empl rate & 42.5 & 9.58 & 103 \\
Non-empl rate corrected & 34.0 & 7.55 & 103 \\
Germany & & & \\
\hline Value added per worker & 52901 & 8134 & 96 \\
Local CPI & 100.0 & 14.18 & 96 \\
Local housing price & 100.0 & 18.53 & 96 \\
Nominal wage - daily & 91.6 & 11.25 & 96 \\
Real wage - daily & 92.3 & 10.76 & 96 \\
Non-empl rate & 27.9 & 3.59 & 96 \\
\hline
\end{tabular}

Note: Value-added is computed across all industries in each geographic area, as calculated by the OECD (Germany) and ISTAT (Italy), and it is divided by employment in the corresponding area. Housing prices are average prices for a square meter with similar characteristics in each area. The Local CPI is constructed using those housing prices according to the method describes in Section IV. Nominal wages are obtained after controlling for individual characteristics such as age, education, gender, and industry, as explained in Section IV. Note that for Italy we have "hourly" wages net of taxes, while for Germany we have "daily" wages gross of taxes. Real wages are deflated using Local CPI. Non-employment refers to the number of people age 15-64 out of employment over the total population of that age group. For Italy, we also report non-employment corrected for the presence of informal work 
Table A-2: $R^{2}$ from a regression of individual wages on worker characteristics, industry and year fixed effects

\begin{tabular}{lcc}
\hline & $(1)$ & $(2)$ \\
& Italy & Germany \\
\hline Without province FE & .352 & .389 \\
With province FE & .36 & .463 \\
Difference & .008 & .074 \\
\hline
\end{tabular}

Note: the first row of this table reports the $R^{2}$ of regressions of individual wages on worker characteristics (gender, age, age squared and education), industry and year fixed effects, for Italy and Germany respectively. The second row reports the $R^{2}$ of the same regressions when province fixed effects are added to the specification. The third row reports the change in the $R^{2}$ deriving from the inclusion of province fixed effects. Data refer to 2009-2013 for Italy and to 1992-2014 for Germany. 
Table A-3: Nominal and real wages corrected for taxes

\begin{tabular}{lcccc}
\hline & \multicolumn{5}{c}{ North - South } \\
& Uncorrected & \multicolumn{2}{c}{ Corrected } \\
\hline & $(1)$ & $(2)$ & $(3)$ & $(4)$ \\
& nominal & real & nominal - corr & real - corr \\
\hline \% Difference & 0.0425 & -0.0921 & 0.0717 & -0.0629 \\
& $(0.003)$ & $(0.017)$ & $(0.004)$ & $(0.017)$ \\
\hline Year FE: & Yes & Yes & Yes & Yes \\
Provinces: & 103 & 103 & 103 & 103 \\
\hline
\end{tabular}

Note: This table reports North-South differences in mean conditional wages obtained from regressions of log mean conditional wages on a dummy for the North. Columns 1 and 2 report, for convenience, the same estimates of Table 7 for Italy, based on wages net of taxes. Columns 3 and 4 are based instead on estimated wages gross of taxes. Wages used for Italy in the first two columns are from Istat and are net of taxes. To generate the corrected wages used in the remaining columns, we take the mean gross and net wages of all full-time workers from the Italian social security agency (INPS) to generate a net/gross ratio for every province. We then correct the Istat wages dividing the net wage of each province by the corresponding net/gross ratio derived from INPS. For nominal wages the data are for years 2009-2013 while for real wages they are for years 2009-2011. All specifications control for year fixed effects. Standard errors are in parentheses 
Table A-4: Counterfactual scenarios - Variant 2 - top 5 provinces

\begin{tabular}{|c|c|c|c|c|c|c|}
\hline \multicolumn{2}{|c|}{ South } & \multicolumn{2}{|c|}{ North } & \multicolumn{3}{|c|}{ Italy } \\
\hline (1) & (2) & (3) & (4) & (5) & (6) & (7) \\
\hline Level & Change & Level & Change & Level & Change & Change $\%$ \\
\hline
\end{tabular}

Average hourly wage: in Euros

\begin{tabular}{llllllll}
\hline Status quo & 8.36 & & 8.68 & & 8.54 & & \\
Counterfactual 1 & 7.38 & -0.98 & 8.39 & -0.30 & 7.94 & -0.60 & -6.99 \\
Counterfactual 2 & 6.92 & -1.45 & 8.23 & -0.46 & 7.64 & -0.90 & -10.50
\end{tabular}

Employment rate: in \% corrected for informal work

\begin{tabular}{lccccccc}
\hline Status quo & 57.32 & & 71.00 & & 64.86 & & \\
Counterfactual 1 & 70.17 & 12.85 & 71.80 & 0.79 & 71.07 & 6.21 & 11.80 \\
Counterfactual 2 & 71.95 & 14.63 & 72.41 & 1.41 & 72.20 & 7.34 & 13.74 \\
\multicolumn{7}{c}{ Aggregate labor income per capita: in Euros per month } \\
Status quo & 766.63 & \multicolumn{7}{c}{986.68} & & 887.89 & & \\
Counterfactual 1 & 828.53 & 61.90 & 963.96 & -22.72 & 903.16 & 15.27 & 3.35 \\
Counterfactual 2 & 795.03 & 28.40 & 953.35 & -33.33 & 882.28 & -5.61 & 0.69 \\
\hline
\end{tabular}

Note: This table is like Table 8 , but the reference group used to calculate $A_{n}, E_{n}$ and $W_{n}$ is the median of the top five provinces in terms of value added, rather than the median of all Northern provinces. 
Table A-5: Counterfactual scenarios - Variant 3: top 10 provinces

\begin{tabular}{|c|c|c|c|c|c|c|c|}
\hline & \multicolumn{2}{|c|}{ South } & \multicolumn{2}{|c|}{ North } & \multicolumn{3}{|c|}{ Italy } \\
\hline & $(1)$ & (2) & (3) & $(4)$ & (5) & $(6)$ & (7) \\
\hline & Level & Change & Level & Change & Level & Change & Change \% \\
\hline \multicolumn{8}{|c|}{ Average hourly wage: in Euros } \\
\hline Status quo & 8.36 & & 8.68 & & 8.54 & & \\
\hline Counterfactual 1 & 7.37 & -0.99 & 8.38 & -0.30 & 7.93 & -0.61 & -7.09 \\
\hline Counterfactual 2 & 6.93 & -1.43 & 8.25 & -0.43 & 7.66 & -0.88 & -10.28 \\
\hline \multicolumn{8}{|c|}{ Employment rate: in \% corrected for informal work } \\
\hline Status quo & 57.32 & & 71.00 & & 64.86 & & \\
\hline Counterfactual 1 & 69.66 & 12.35 & 71.32 & 0.32 & 70.58 & 5.72 & 11.01 \\
\hline Counterfactual 2 & 71.34 & 14.03 & 71.82 & 0.82 & 71.61 & 6.75 & 12.78 \\
\hline \multicolumn{8}{|c|}{ Aggregate labor income per capita: in Euros per month } \\
\hline Status quo & 766.63 & & 986.68 & & 887.89 & & \\
\hline Counterfactual 1 & 821.33 & 54.70 & 956.94 & -29.73 & 896.06 & 8.17 & 2.50 \\
\hline Counterfactual 2 & 790.23 & 23.60 & 948.41 & -38.27 & 877.40 & -10.50 & 0.11 \\
\hline
\end{tabular}

Note: This table is like Table 8, but the reference group used to calculate $A_{n}, E_{n}$ and $W_{n}$ is the median of the top ten provinces in terms of value added, rather than the median of all Northern provinces. 
Table A-6: Counterfactual scenarios - Variant 4: top 20 provinces

\begin{tabular}{|c|c|c|c|c|c|c|c|}
\hline & \multicolumn{2}{|c|}{ South } & \multicolumn{2}{|c|}{ North } & \multicolumn{3}{|c|}{ Italy } \\
\hline & $(1)$ & $(2)$ & (3) & $(4)$ & $(5)$ & $(6)$ & $(7)$ \\
\hline & Level & Change & Level & Change & Level & Change & Change \% \\
\hline \multicolumn{8}{|c|}{ Average hourly wage: in Euros } \\
\hline Status quo & 8.36 & & 8.68 & & 8.54 & & \\
\hline Counterfactual 1 & 7.42 & -0.94 & 8.43 & -0.26 & 7.97 & -0.57 & -6.55 \\
\hline Counterfactual 2 & 7.02 & -1.34 & 8.34 & -0.35 & 7.75 & -0.79 & -9.27 \\
\hline \multicolumn{8}{|c|}{ Employment rate: in \% corrected for informal work } \\
\hline Status quo & 57.32 & & 71.00 & & 64.86 & & \\
\hline Counterfactual 1 & 69.00 & 11.69 & 70.60 & -0.40 & 69.89 & 5.03 & 9.89 \\
\hline Counterfactual 2 & 70.53 & 13.21 & 70.94 & -0.06 & 70.76 & 5.90 & 11.41 \\
\hline \multicolumn{8}{|c|}{ Aggregate labor income per capita: in Euros per month } \\
\hline Status quo & 766.63 & & 986.68 & & 887.89 & & \\
\hline Counterfactual 1 & 819.10 & 52.47 & 952.57 & -34.10 & 892.65 & 4.76 & 2.10 \\
\hline Counterfactual 2 & 791.41 & 24.78 & 946.83 & -39.84 & 877.06 & -10.83 & 0.08 \\
\hline
\end{tabular}

Note: This table is like Table 8, but the reference group used to calculate $A_{n}, E_{n}$ and $W_{n}$ is the median of the top twenty provinces in terms of value added, rather than the median of all Northern provinces. 


\section{Figure A-1: Share of informal employment}
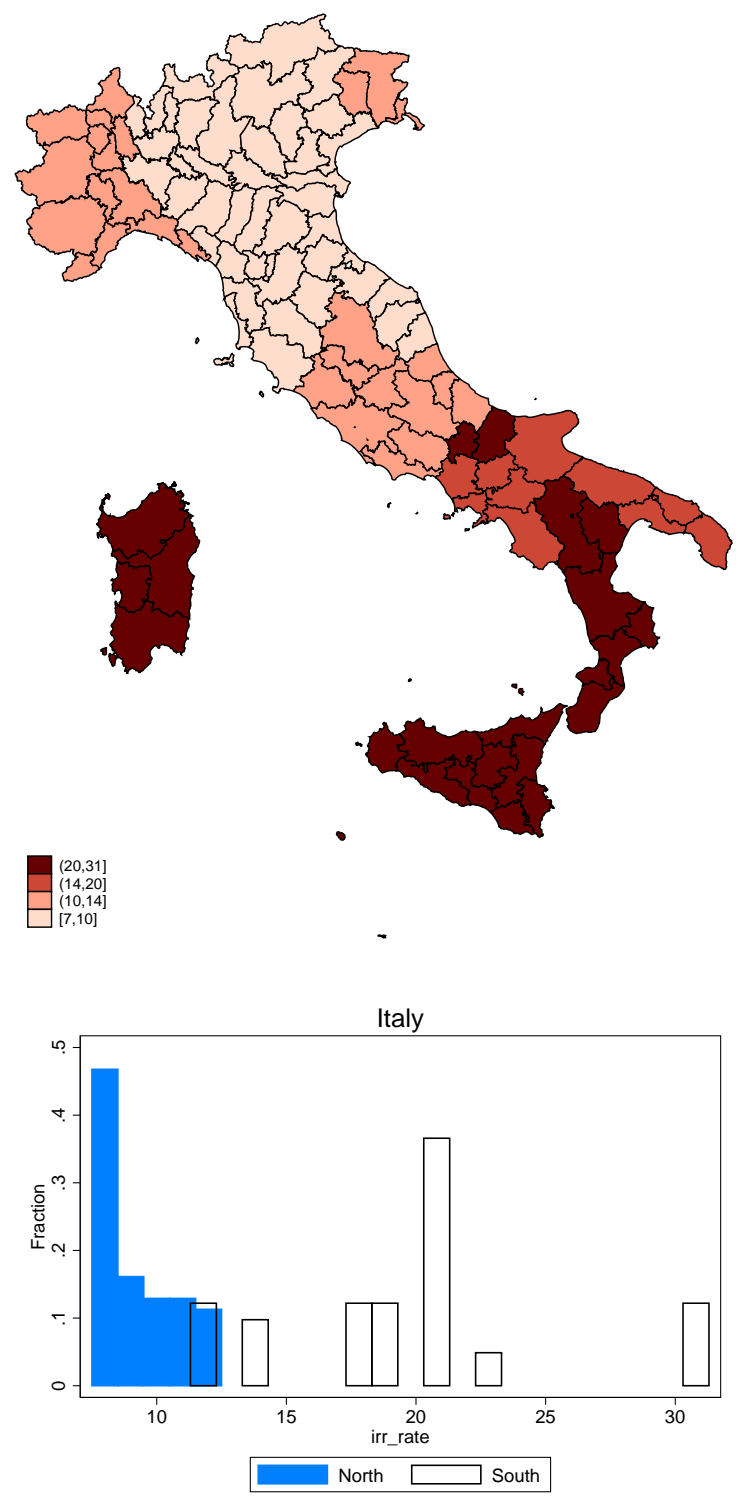

Note: This figure plots deviations from the country mean of the share of irregular employment out of total employment of each province in 2010. Means are not weighted by population. The share of irregular employment is provided by Istat, 2014. 
Figure A-2: Non-employment rate corrected for informal employment
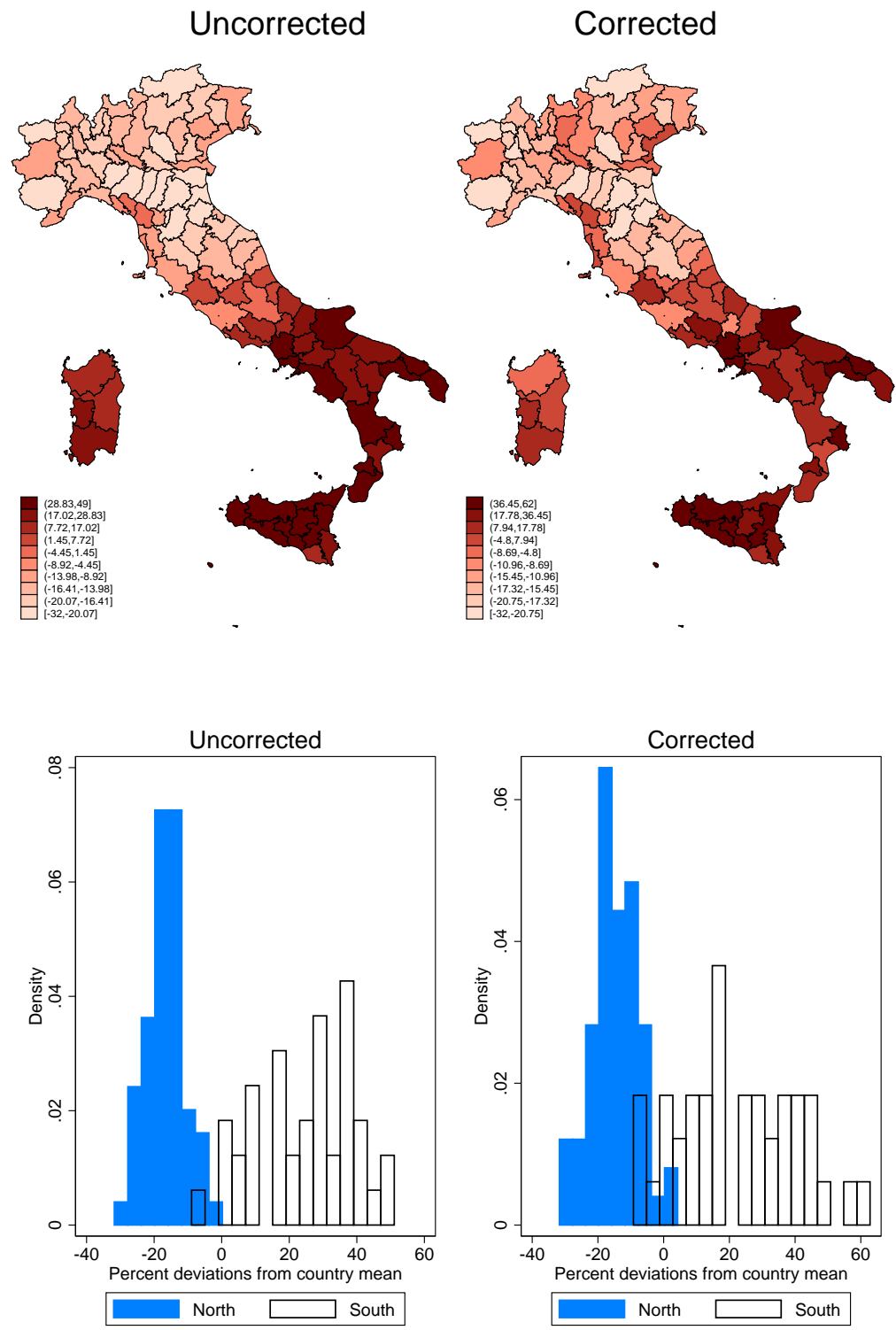

Note: To account for employment in the informal sector in Italy we compute an "informal labor market corrected" employment rate by adjusting our employment rate to the fact that we only observe a proportion $1-e_{\text {inf }}$ (1-rate of informal employment) of actual employment. We thus inflate the official employment rate by a factor $\frac{1}{1-e_{i n f}}$. This figure plots deviations from the country mean of the non-employment rate of each province in 2010, comparing the corrected and uncorrected figures. Means are not weighted by population. The share of irregular employment is provided by Istat, 2014. 


\section{Figure A-3: Housing costs}
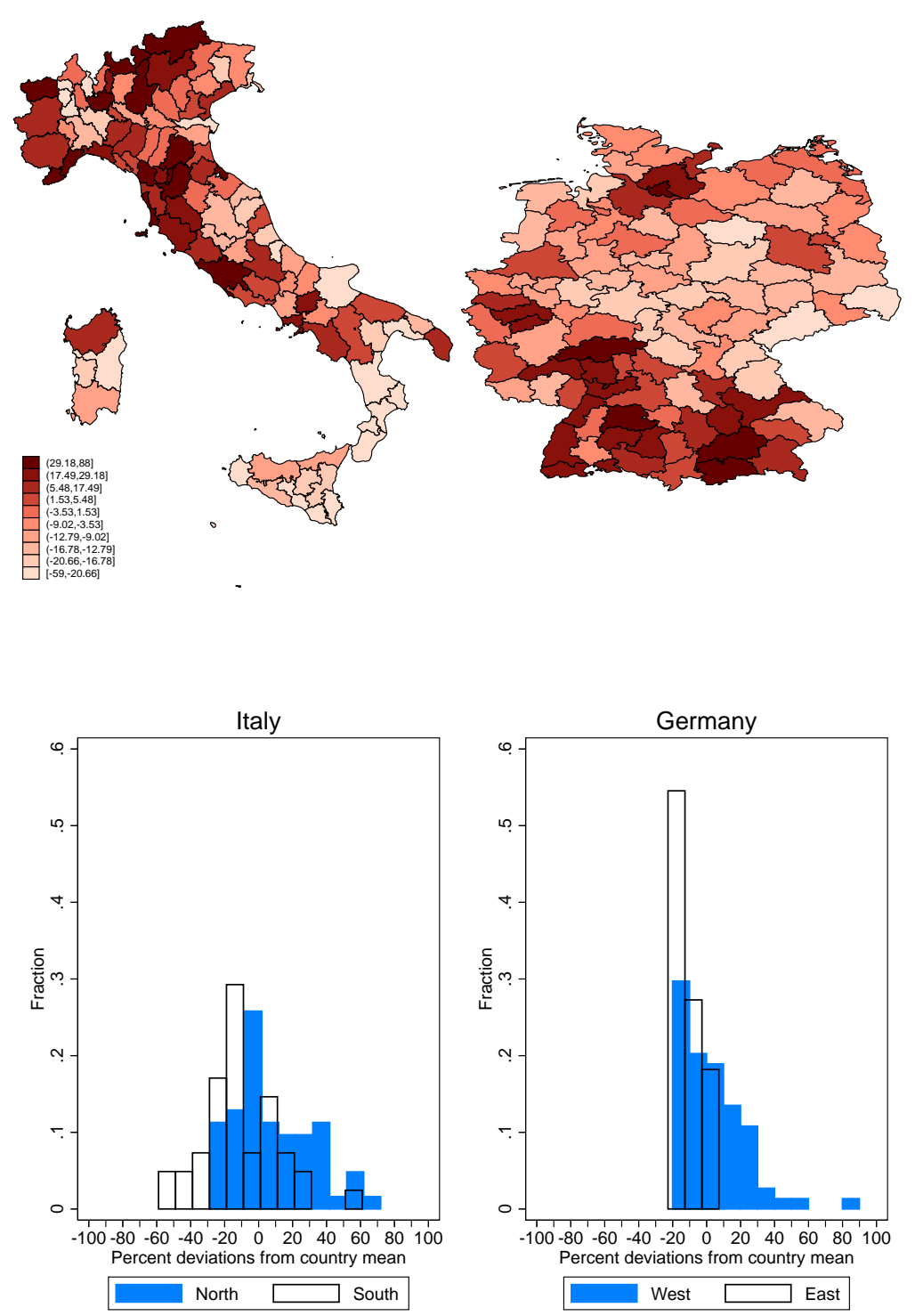

Note: This figure plots deviations from the country mean of the housing price index of each province in 2010. Means are not weighted by population. 


\section{Figure A-4: Local cost of living index}
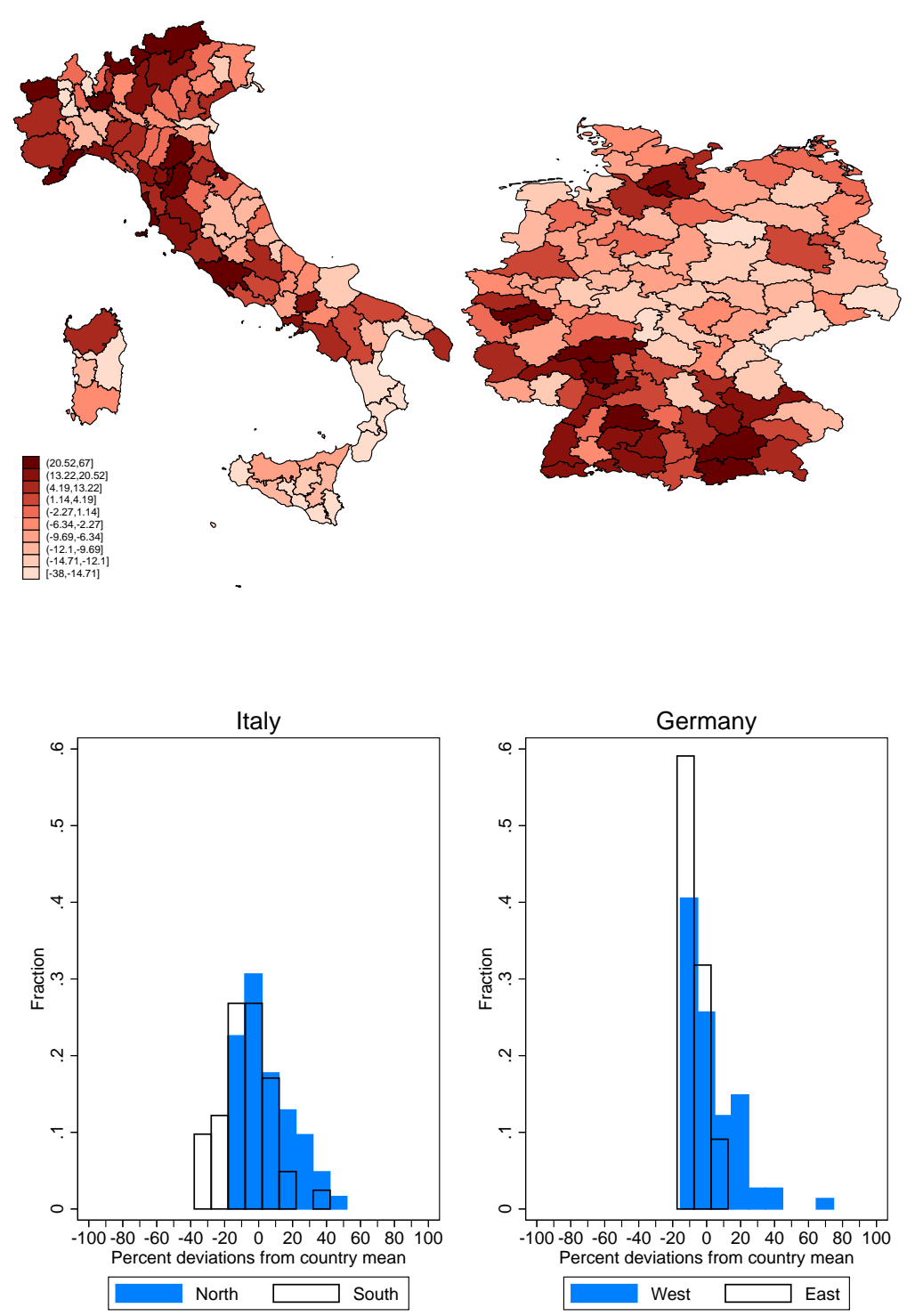

Note: This figure plots deviations from the country mean of the consumer price index of each province in 2010. Means are not weighted by population. 